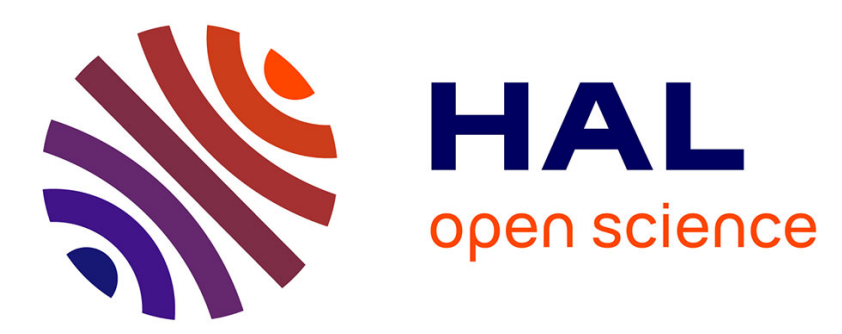

\title{
In silico approach to quantify nucleus self-deformation on micropillared substrates
}

Solène Mondesert-Deveraux, Denis Aubry, Rachele Allena

\section{To cite this version:}

Solène Mondesert-Deveraux, Denis Aubry, Rachele Allena. In silico approach to quantify nucleus self-deformation on micropillared substrates. Biomechanics and modeling in mechanobiology, 2019, 18 (5), pp.1281-1295. 10.1007/s10237-019-01144-2 . hal-02378736

\section{HAL Id: hal-02378736 \\ https://hal.science/hal-02378736}

Submitted on 25 Nov 2019

HAL is a multi-disciplinary open access archive for the deposit and dissemination of scientific research documents, whether they are published or not. The documents may come from teaching and research institutions in France or abroad, or from public or private research centers.
L'archive ouverte pluridisciplinaire HAL, est destinée au dépôt et à la diffusion de documents scientifiques de niveau recherche, publiés ou non, émanant des établissements d'enseignement et de recherche français ou étrangers, des laboratoires publics ou privés. 


\title{
In silico approach to quantify nucleus self-deformation on micropillared substrates
}

\author{
Solenne Mondésert-Deveraux ${ }^{1} \cdot$ Denis Aubry $^{1} \cdot$ Rachele Allena $^{2}$
}

\begin{abstract}
Considering the major role of confined cell migration in biological processes and diseases, such as embryogenesis or metastatic cancer, it has become increasingly important to design relevant experimental set-ups for in vitro studies. Microfluidic devices have recently presented great opportunities in their respect since they offer the possibility to study all the steps from a suspended to a spread, and eventually crawling cell or a cell with highly deformed nucleus. Here, we focus on the nucleus self-deformation over a micropillared substrate. Actin networks have been observed at two locations in this set-up: above the nucleus, forming the perinuclear actin cap (PAC), and below the nucleus, surrounding the pillars. We can then wonder which of these contractile networks is responsible for nuclear deformation. The cytoplasm and the nucleus are represented through the superposition of a viscous and a hyperelastic material and follow a series of processes. First, the suspended cell settles on the pillars due to gravity. Second, an adhesive spreading force comes into play, and then, active deformations contract one or both actin domains and consequently the nucleus. Our model is first tested on a flat substrate to validate its global behaviour before being confronted to a micropillared substrate. Overall, the nucleus appears to be mostly pulled towards the pillars, while the mechanical action of the PAC is weak. Eventually, we test the influence of gravity and prove that the gravitational force does not play a role in the final deformation of the nucleus.
\end{abstract}

Keywords Mechanical forces $\cdot$ Nucleus self-deformation $\cdot$ Micropillared substrate $\cdot$ In silico model

\section{Introduction}

To survive, cells need to constantly adapt to their environment by altering their morphology and physiology (Benjamin and Hillen 2003; Mammoto and Ingber 2010; Versaevel et al. 2012; Swift et al. 2013). During confined migration, for instance, cells undergo important strains in order to be able to squeeze enough and migrate through sub-cellular and sub-nuclear pores as far as the nucleus, the stiffest cellular

Rachele Allena

rachele.allena@ensam.eu

1 Laboratoire MSSMat UMR CNRS 8579, CentraleSupélec, Université Paris-Saclay, 8-10 Rue Joliot Curie, Gif-Sur-Yvette, Paris, France

2 LBM/Institut de Biomécanique Humaine Georges Charpak, Arts et Metiers ParisTech, 151 Boulevard de l'Hôpital, Paris, France organelle, enables it (Friedl et al. 2011; Wolf et al. 2013). Impressively, cancerous cells are even able to break the nuclear lamina to soften the nucleus and to invade healthy tissues across tiny pores (Denais et al. 2016; Bell and Lammerding 2016). As such, the evolution of nuclear morphology can be used as a biomarker in the diagnosis and prognosis of cancer patients (Schirmer and de las Heras 2014; Ermis et al. 2016).

In order to characterize such cells and analyse their behaviour in confined environments, patterned microfluidic devices are often used (Lu et al. 2004; Rosenbluth et al. 2008; Davidson et al. 2009). Micropillars are most commonly employed as an array of thin beams in traction force microscopy to access the interaction forces between a cell and its substrate (Tan et al. 2003; du Roure et al. 2005; Ghibaudo et al. 2011). Additionally, by controlling the material used, the size of the pillars and the gap size between pillars, they can serve to control the shape of the nucleus (Pan et al. 2012; Hanson et al. 2015) and investigate the process of nuclear self-deformation induced by mechanical forces generated by the topological surface (Davidson et al. 2010; 
Badique et al. 2013; Liu et al. 2017, 2018). These recent experiments offer a new insight on nuclear deformation and raise further questions: is gravity driving this movement (Pan et al. 2012)? Is the nucleus being pulled or pushed (Davidson et al. 2010; Badique et al. 2013; Hanson et al. 2015)? Indeed, intense contractile actin fibres have been observed at two locations in the cell: above the nucleus and around the pillars beneath the nucleus (Hanson et al. 2015; Davidson et al. 2015; Fig. 1a). The fibres above the nucleus form a dome-like actin cap called the perinuclear actin cap (PAC) (Khatau et al. 2009). This PAC domain has three fixation points in the cell: it is anchored at its both ends to a specific type of focal adhesions (FAs) and, in its middle, to the nuclear lamina via linker of nucleoskeleton and cytoskeleton (LINC) complex (Maninova et al. 2017; Fig. 1b). The PAC thus forms a direct mechanosensing link from the extracellular matrix to the nucleus (Kim et al. 2012) and has been found to be a regulator of cell migration (Kim et al. 2014).

When using microfluidic devices, one may observe successive steps. From a suspended state, the cell gently comes in contact with the pillars, adheres and then spreads, polarizes and eventually crawls over the substrate.

Spreading can be divided into two main phases. The first phase is a completely passive one during which the cell settles on the substrate under the action of gravity only and

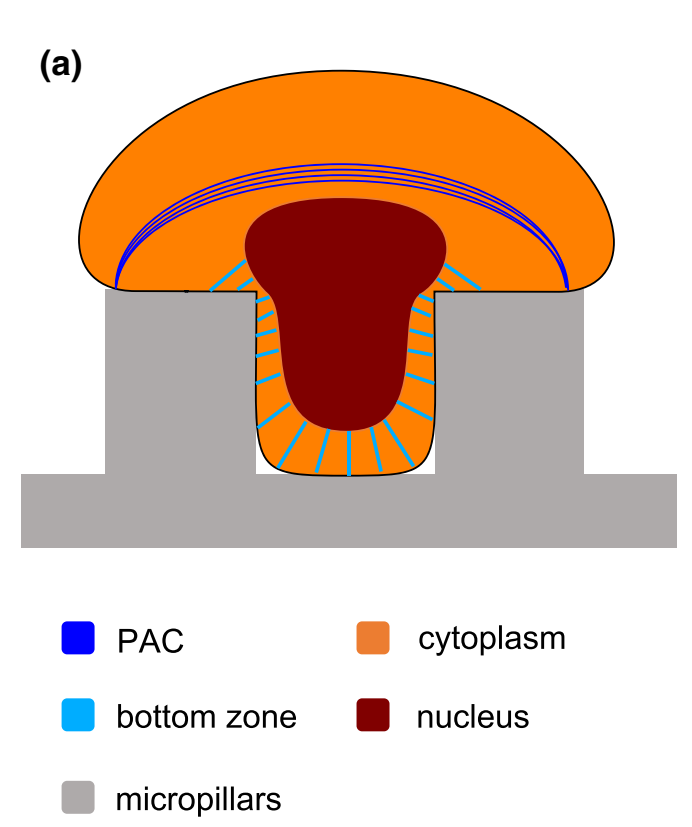

Fig. 1 a Sketch of the cell and nucleus morphologies once it has penetrated between the micropillars. The actin fibres constituting the PAC and the bottom zone are represented in blue and green, respectively. The former are tangentially oriented, whereas the latter are radially oriented. b Geometrical representation of the cell components as well as the PAC $\left(\Omega_{\text {PAC }}\right)$ and the bottom zone $\left(\Omega_{\text {bottom }}\right)$ in deforms depending on its own overall stiffness. The second phase is an active one during which the cell protrudes and contracts through polymerization and depolymerization.

Once the cell has touched the underneath substrate, it starts developing the FAs to create a mechanical link between the intra-cellular actin filaments and the substrate surface (Abercrombie et al. 1970). Then, FAs play the role of anchoring points that restrain cell contraction while promoting cell protrusion at the leading edge and nucleus self-deformation through the pillars (Morgan et al. 2007; Geiger et al. 2009; Liu et al. 2017, 2018). It has been observed that the nucleus may undergo large and severe deformations as a function of the cellular phenotype and the nuclear size. Additionally, external forces may highly modify the nucleus shape as well as the chromatin organization inside it and consequently its gene expression. According to these experimental observations, it is essential to decipher the mechanical processes triggering the nucleus large strains which may be responsible for important cellular functions such as migration or proliferation.

Our main objective is to analyse the nuclear behaviour as a function of the micropillared substrate geometry (i.e. pillars height, width and interspace) and the contractile fibre network formed by the cell around the nucleus itself. This particular aspect has been so far poorly observed and investigated from an experimental point of view and never been

(b)

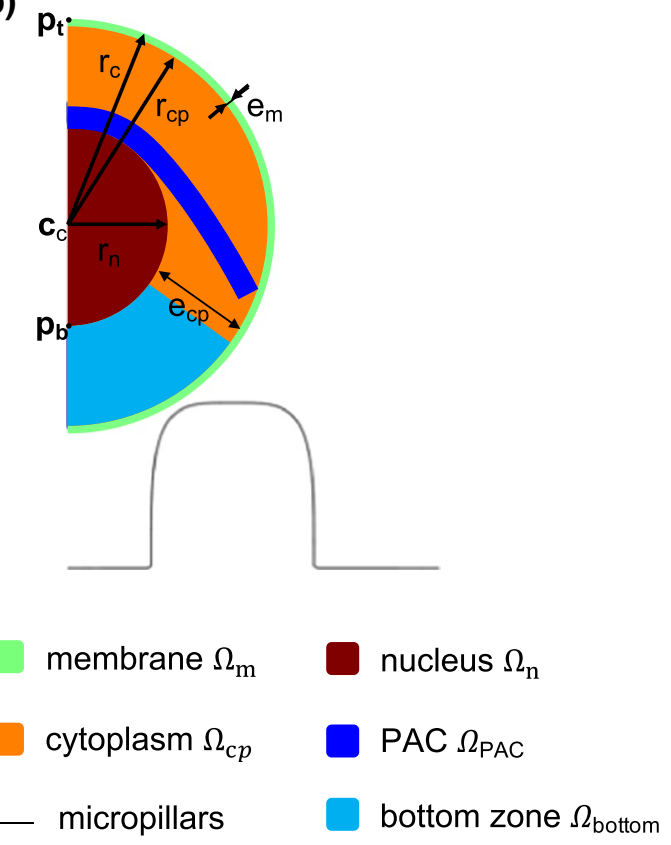

our numerical model at $t=0 . r_{\mathrm{c}}$ and $r_{\mathrm{n}}$ are the cell and nucleus radii, respectively, $r_{\mathrm{cp}}$ and $e_{\mathrm{cp}}$ the external radius and the thickness of the cytoplasm, and $e_{\mathrm{m}}$ the membrane thickness. $\boldsymbol{c}_{\mathrm{c}}, \boldsymbol{p}_{\mathrm{b}}$ and $\boldsymbol{p}_{\mathrm{t}}$ are the cell centre and a bottom and a top points, respectively, used for postprocessing 
numerically modelled. Therefore, we believe that our computational approach can bring new insights in understanding how the nucleus responds to its environment and what are the mechanical forces driving such behaviour.

\subsection{Modelling of cell-substrate interaction}

Most of the models that can be found in the literature focus on the interactions between the cell and a flat substrate and can be divided into three main categories: analytical, discrete and continuum models.

Analytical models do not require extensive computational implementation, but they only provide global information of spreading dynamics in various conditions. The very first models aimed at investigating the evolution (i.e. progression in size and morphology) of the contact surface (Cuvelier et al. 2007) or the influence of ligand density gradient on cell kinematics (Sarvestani and Jabbari 2008). More recently, some models have also taken into account the active forces triggered by the acto-myosin network (Nisenholz et al. 2014) or the mechanotransduction feedback from the nucleus to the FAs (Cao et al. 2015).

Discrete models allow to analyse the intra-cellular rearrangement since they physically represent the cytoskeleton as a network of connected bars (i.e. tensegrity models) (Ingber 2003). Tensegrity has been coupled to divided-media theory (or cytoskeleton divided medium method) to assess mechanotransduction during spreading with just one type of tensile filaments (Milan et al. 2013) or with the actin filaments, intermediate filaments and microtubules (Fang and Lai 2016).

In continuum models, whether they are two (2D) or three (3D) dimensional, the cell is considered as a continuum solid or fluid domain and no organelle is physically represented, but the nucleus. Such models are able to provide information at both the global and the local levels. Some studies focus on the first step of the spreading mechanism, modelling receptor-ligand binding, which can only lead to a limited deformation of the cell (Liu et al. 2007; Golestaneh and Nadler 2016), although the use of membrane reservoirs can influence its extent (Étienne and Duperray 2011). Another method consists in modelling spreading mechanism through a unique force accounting for both ligand-receptor binding and active acto-myosin cytoskeleton tension forces, and it can be used to study more specifically the dynamics of the nucleus during cell spreading (Zeng and Li 2011a, 2012). One model proposed a two-step process: (1) a purely passive spreading and (2) an active actin action to help the cell to spread further (Fan and Li 2015a, b). As for modelling the interactions between the cell and a micropatterned substrate, a first attempt was made by Hanson et al. (2015) to investigate whether the nucleus is being pulled or pushed in pillars groves. Nonetheless, the question is still open and mainly motivates our present study.
In line with our previous works (Allena and Aubry 2012; Deveraux et al. 2017), we propose a continuum finite elements model to simulate cell behaviour over the flat and micropatterned substrates coated with adhesive fibronectin. As mentioned above, our main objective is to depict the nucleus self-deformation as a function of the micropillared substrate geometry and the actin network around the nucleus itself. This will allow us to computationally determine whether the nucleus is able or not to penetrate between the pillars and what mechanical forces drive such penetration.

The 2D cell approximation in our model is constituted of the nucleus, the cytoplasm and the membrane and is described as a visco-hyperelastic material under large deformations. During the process, the cell is submitted to (1) gravity, (2) a spreading and adhesion force, (3) a contact force with the substrate surface and (4) an active contractile strain. The active contractile strain allows us to explore whether the actin filaments on the top and at the bottom of the nucleus push or pull it down, respectively.

\section{The model}

\subsection{Cell geometry and constitutive laws}

Let us consider the initial cellular 2D domain $\Omega_{\mathrm{c}}$ constituted by the nucleus $\Omega_{\mathrm{n}}$ and the cytoplasm $\Omega_{\mathrm{cp}}$, which includes the membrane $\Omega_{\mathrm{m}}$ (Fig. 1b). Because of the symmetry conditions, the nucleus is a semicircle of radius $r_{\mathrm{n}}$, whereas the cytoplasm and the membrane are two semi-annuli. The cytoplasm has an internal radius $r_{\mathrm{n}}$, an external radius $r_{\mathrm{cp}}$ and a thickness $e_{\mathrm{cp}}$. The membrane has an internal radius $r_{\mathrm{cp}}$, an external radius $r_{\mathrm{c}}$ and a thickness $e_{\mathrm{m}}$. Each component of the cell is defined by a spatial characteristic function $g_{i}$ which is the composition of a regularized Heaviside function $H$ and a level set function $l_{i}$ (where the subscript $i$ indicates the component). The former is a classical step function which value is 0 for negative argument and 1 for positive argument. Then, in our model, the function $g_{i}$ is positive inside the corresponding domain and negative outside and reads

$$
\begin{aligned}
& g_{\mathrm{c}}=H \circ l_{\mathrm{c}}=H \circ\left(\boldsymbol{p}-\boldsymbol{c}_{\mathrm{c}, \mathrm{p}}^{2}-r_{\mathrm{c}}^{2}\right) \\
& g_{\mathrm{n}}=H \circ l_{\mathrm{n}}=H \circ\left(\boldsymbol{p}-\boldsymbol{c}_{\mathrm{c}, \mathrm{p}}^{2}-r_{\mathrm{n}}^{2}\right) \\
& g_{\mathrm{cp}}=H \circ l_{\mathrm{cp}}-g_{\mathrm{n}}=H \circ\left(\boldsymbol{p}-\boldsymbol{c}_{\mathrm{c}, \mathrm{p}}^{2}-r_{\mathrm{cp}}^{2}\right)-g_{\mathrm{n}} \\
& g_{\mathrm{cp}}=g_{\mathrm{c}}-g_{\mathrm{n}} \\
& g_{\mathrm{m}}=g_{\mathrm{c}}-g_{\mathrm{cp}}-g_{\mathrm{n}}
\end{aligned}
$$


with $p$ being the initial configuration ( $t=0, t$ being the time) of any point in the system and $\boldsymbol{c}_{\mathrm{c}, \mathrm{p}}$ the centre of the cell of coordinates $\left(c_{x}, c_{y}\right)$.

In the cell, both the cytoplasm and the nucleus are constituted by a solid and a fluid phase, as proposed in Fig. 2. The nucleus is composed by the lamina (solid) and the nucleoplasm (fluid), and the cytoplasm by the cytoskeleton and the membrane (solid) and the cytosol (fluid).

As in a Kelvin-Voigt model, the overall stress $\boldsymbol{S}_{\mathrm{c}}$ and deformation $\boldsymbol{F}_{\mathrm{c}}$ of the cell are given by

$S_{\mathrm{c}}=S_{\mathrm{s}}+S_{\mathrm{f}}$

$\boldsymbol{F}_{\mathrm{c}}=\boldsymbol{F}_{\mathrm{s}}=\boldsymbol{F}_{\mathrm{f}}$

where the subscripts $s$ and $f$ indicate solid and fluid, respectively.

\subsubsection{The solid phase}

The second Piola-Kirchhoff stress $\boldsymbol{S}_{\mathrm{s}}$ in the solid phase can be expressed as

$\boldsymbol{S}_{\mathrm{s}}=J_{\mathrm{a}} \boldsymbol{F}_{\mathrm{a}}^{-1} \boldsymbol{S}_{\mathrm{e}} \boldsymbol{F}_{\mathrm{a}}^{-\mathrm{T}}$

where $\boldsymbol{F}_{\mathrm{a}}$ is the active deformation tensor which will be detailed later in Sect. 2.2.5, $S_{\mathrm{e}}$ is the second Piola-Kirchhoff stress for the elastic part of the solid phase and $J_{\mathrm{a}}$ is its determinant. In fact, as proposed in the previous works (Rodriguez et al. 1994; Lubarda 2004; Muñoz et al. 2007; Cherubini et al. 2008; Allena et al. 2010; Ambrosi et al. 2011; Nobile et al. 2012; Allena and Aubry 2012; Golestaneh and
Nadler 2016; Deveraux et al. 2017), we model the cell contractility as an active strain through the decomposition of the deformation gradient $\boldsymbol{F}_{\mathrm{c}}$ (see Fig. 2) which then reads

$\boldsymbol{F}_{\mathrm{c}}=\boldsymbol{F}_{\mathrm{e}} \boldsymbol{F}_{\mathrm{a}}$

with $\boldsymbol{F}_{\mathrm{e}}$ being the elastic deformation gradient tensor. As shown in Ambrosi and Pezzuto (2011), the active strain approach is mathematically more robust than the active stress one and if the active strain can be reinterpreted in terms of active stress, no new free parameters need to be tuned. Additionally, some interesting works with promising results have been proposed to investigate the physiological effectiveness of the obtained model (Stålhand et al. 2008; Murtada et al. 2010).

Among the different isotropic material models available to describe the cell as a hyperelastic solid continuum, one may distinguish between (1) standard Saint-Venant material (Allena and Aubry 2012; Fan and Li 2015b) whose elastic energy depends on the first invariant $I_{1}=\operatorname{Tr}\left(\boldsymbol{C}_{\mathrm{e}}\right)$ and $I_{2, \mathrm{SV}}=\operatorname{Tr}\left(\boldsymbol{C}_{\mathrm{e}}^{2}\right)$, with $\operatorname{Tr}$ being the trace of a tensor and the $\boldsymbol{C}_{\mathrm{e}}=\boldsymbol{F}_{\mathrm{e}}^{\mathrm{T}} \boldsymbol{F}_{\mathrm{e}}$ the symmetric right Cauchy-Green tensor, (2) the neo-Hookean material (Jean et al. 2003; Mokbel et al. 2017) which depends on $I_{1}$ and on the third invariant $I_{3}=\operatorname{det}\left(\boldsymbol{C}_{\mathrm{e}}\right)$, with det being the determinant of a tensor, (3) the polyconvex Mooney-Rivlin material (Zeng and Li $2011 \mathrm{~b}$; Wang et al. 2017) which depends on $I_{1}, I_{3}$ and $I_{2}=\operatorname{det}\left(\boldsymbol{C}_{\mathrm{e}}\right) \operatorname{Tr}\left(\boldsymbol{C}_{\mathrm{e}}^{-1}\right)$ (Holzapfel 2000) and (4) the Yeoh model which nonlinearly depends on $I_{1}, I_{2}$ and $I_{3}$ (Yeoh 1993).

In the cell, the cytoskeleton and the lamina are composed by different types of biopolymers (i.e. actin fibres, intermediate filaments, microtubules, etc.), which may
Fig. 2 Different phases of the constitutive model used to describe the mechanical behaviour of the cytoplasm and the nucleus

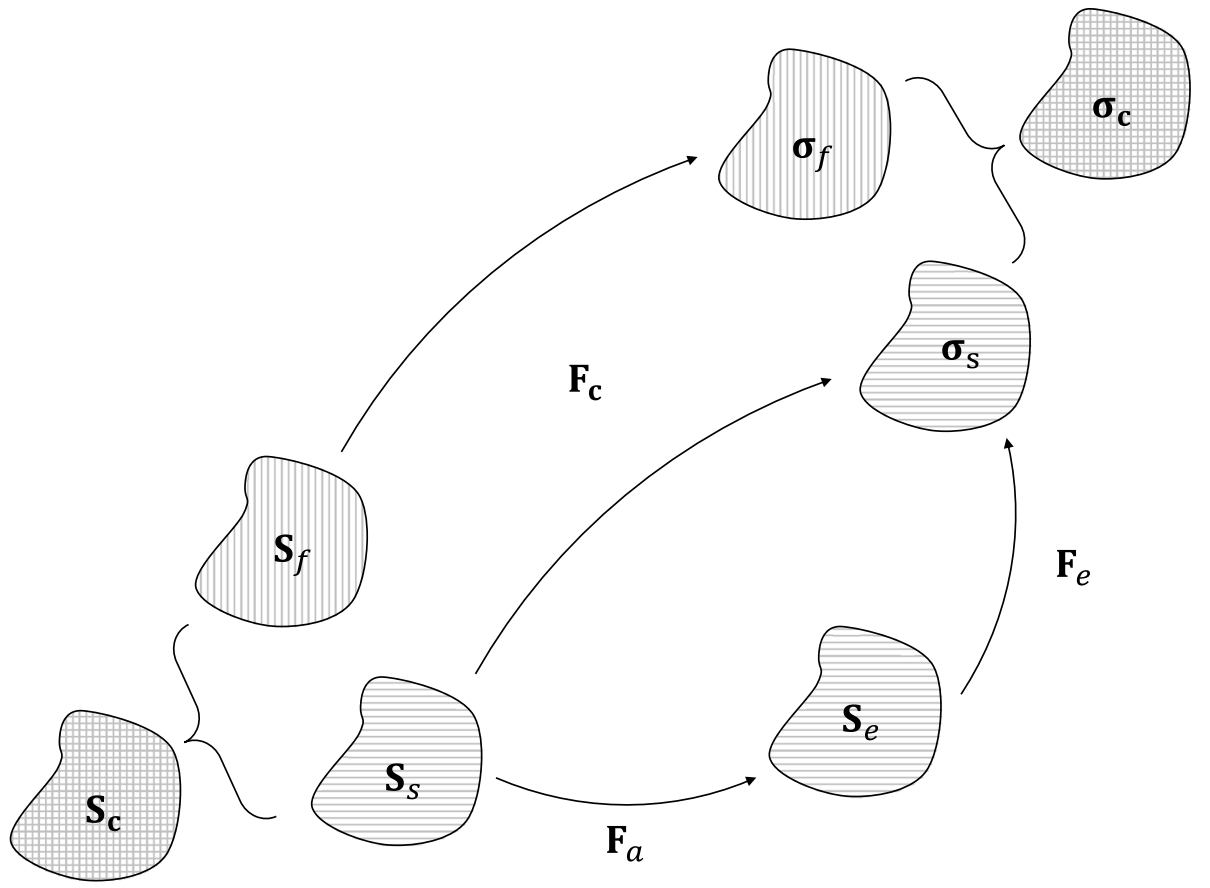


undergo a significant strain stiffening when deformed. It is the case for actin fibres and strains less than $10 \%$, as reported in Storm et al. (2005) and Erk et al. (2010), but no experimental data are available for strains higher than $10 \%$. According to the graphics presented in these works, one may deduce that the stiffness of the actin fibres increases exponentially as the strain increases too. Such a behaviour is unlikely to be mechanically realistic and would completely inhibit the whole cell deformation. However, it is possible that actin fibres undergo sequential deformation (i.e. stiffening) and unfolding (i.e. relaxation), which results in a saw-tooth pattern of the stiffness as presented in Bao and Suresh (2003). Given such observations and since in our model large strains occur (especially for the cytoskeleton), we have decided to employ a visco-hyperelastic Yeoh material model whose parameters have been reasonably tuned in order to take into account the stiffening for small deformations.

The material energy $W_{Y}$ can be written as

$$
\begin{aligned}
W_{Y}= & \alpha_{1}\left(I_{1}-3 I_{3}^{\frac{1}{3}}\right)+\alpha_{2}\left(I_{1}-3 I_{3}^{\frac{1}{3}}\right)^{2}+\alpha_{3}\left(I_{1}-3 I_{3}^{\frac{1}{3}}\right)^{3} \\
& +\beta\left(I_{2}-3 I_{3}^{\frac{1}{3}}\right)+\Gamma\left(J_{\mathrm{e}}\right)
\end{aligned}
$$

with $\alpha_{1}, \alpha_{2}, \alpha_{3}$ and $\beta$ being the scalars and $\Gamma$ a convex function of $J_{\mathrm{e}}=\operatorname{det}\left(\boldsymbol{F}_{\mathrm{e}}\right)=\operatorname{det}\left(\boldsymbol{C}_{\mathrm{e}}\right)^{1 / 2}$. More 4 specifically, we consider $\Gamma=\frac{\lambda_{Y}}{2} \ln \left(J_{\mathrm{e}}\right)^{2}-3 \alpha_{1} J_{\mathrm{e}} / 3-3 \beta J_{\mathrm{e}} / 3$ as defined in Fried and Johnson (1988), and according to Bonet et al. (2015), we can write

$\alpha_{1}+\beta=\frac{\mu_{\mathrm{e}}}{2}$

$\lambda_{Y}=\lambda_{\mathrm{e}}+\frac{2}{3} \mu_{\mathrm{e}}$

while $\alpha_{2}=-\gamma \alpha_{1}=-\gamma\left[\frac{E_{\mathrm{c}}\left(1+v_{\mathrm{c}}\right)}{2}\right]$ and $\alpha_{3}=\gamma \alpha_{1}=\gamma\left[\frac{E_{\mathrm{c}}\left(1+v_{\mathrm{c}}\right)}{2}\right]$, with $\gamma$ being a scalar, $E_{\mathrm{c}}=E_{\mathrm{n}} g_{\mathrm{n}}+E_{\mathrm{cp}} g_{\mathrm{cp}}$, $v_{\mathrm{c}}$ the cell Poisson's ratio, $\beta=0.2 \frac{\mu_{\mathrm{e}}}{2}, \mu_{\mathrm{e}}$ and $\lambda_{\mathrm{e}}$ the cell Lamé's coefficients. The second Piola-Kirchhoff tensor $S_{\mathrm{e}}$ is derived from $W_{Y}$ as follows:

$\boldsymbol{S}_{\mathrm{e}}=2 \frac{\partial W_{Y}}{\partial \boldsymbol{C}_{\mathrm{e}}}$

Through some algebraic manipulations, Eq. (13) becomes

$$
\begin{aligned}
\boldsymbol{S}_{\mathrm{e}}= & 2\left[\alpha_{1}+2 \alpha_{2}\left(I_{1}-3 I_{3}^{\frac{1}{3}}\right)+3 \alpha_{3}\left(I_{1}-3 I_{3}^{\frac{1}{3}}\right)^{2}\right]\left(\boldsymbol{I}-I_{3}^{\frac{1}{3}} \boldsymbol{C}_{\mathrm{e}}^{-1}\right) \\
& +2 \beta\left(\operatorname{Tr} \boldsymbol{C}_{\mathrm{e}} \boldsymbol{I}-\boldsymbol{C}_{\mathrm{e}}-2 I_{3}^{\frac{2}{3}} \boldsymbol{C}_{\mathrm{e}}^{-1}\right)+\Gamma^{\prime} \boldsymbol{C}_{\mathrm{e}}^{-1}
\end{aligned}
$$

\subsubsection{The fluid phase}

Here, we consider a classical Newtonian viscous fluid which must be described in the Lagrangian configuration to ensure the compatibility with the solid phase.

The Cauchy stress tensor $\sigma_{\mathrm{f}}$ is expressed as

$\boldsymbol{\sigma}_{\mathrm{f}}=\lambda_{\mathrm{f}} \operatorname{Tr}\left(\boldsymbol{D}_{\mathrm{f}}\right) \boldsymbol{I}+2 \mu_{\mathrm{f}} \boldsymbol{D}_{\mathrm{f}}$

where $\lambda_{\mathrm{f}}$ and $\mu_{\mathrm{f}}$ are the isotropic and deviatoric viscosities, respectively. $\boldsymbol{D}_{\mathrm{f}}$ is the Eulerian cell rate of deformation gradient which is expressed with respect to the Lagrangian coordinates as

$\boldsymbol{D}_{\mathrm{f}}=\mathbf{F}_{\mathrm{f}}^{-\mathrm{T}} \frac{\mathrm{d} \mathbf{C}_{\mathrm{f}}}{\mathrm{d} t} \mathbf{F}_{\mathrm{f}}^{-1}$

with the superscript $T$ indicating the transpose of a matrix.

Since $\mathbf{F}_{\mathrm{f}}=\mathbf{F}_{\mathrm{c}}$ and $\mathbf{C}_{\mathrm{f}}=\mathbf{C}_{\mathrm{c}}$, the Cauchy-Green tensors of the fluid phase and of the global cell, respectively, and by substituting the expression of $\boldsymbol{\sigma}_{\mathrm{f}}$ and $\boldsymbol{D}_{\mathrm{f}}$, we obtain

$\mathbf{S}_{\mathrm{f}}=J_{\mathrm{c}} \mathbf{F}_{\mathrm{c}}^{-1} \boldsymbol{\sigma}_{\mathrm{c}} \mathbf{F}_{\mathrm{c}}^{-\mathrm{T}}=\frac{J_{\mathrm{c}} \lambda_{\mathrm{f}}}{2} \operatorname{Tr}\left(\mathbf{F}_{\mathrm{c}}^{-\mathrm{T}} \frac{\mathrm{d} \mathbf{C}_{\mathrm{c}}}{\mathrm{d} t} \mathbf{F}_{\mathrm{c}}^{-1}\right) \boldsymbol{C}_{\mathrm{c}}^{-1}+J_{\mathrm{c}} \mu_{\mathrm{f}} \boldsymbol{C}_{\mathrm{c}}^{-1} \frac{\mathrm{d} \mathbf{C}_{\mathrm{c}}}{\mathrm{d} t} \boldsymbol{C}_{\mathrm{c}}^{-1}$

Finally, given $\frac{\mathrm{d} C_{\mathrm{c}}^{-1}}{\mathrm{~d} t}=-\boldsymbol{C}_{\mathrm{c}}^{-1} \frac{\mathrm{d} \boldsymbol{C}_{\mathrm{c}}}{\mathrm{d} t} \boldsymbol{C}_{\mathrm{c}}^{-1}$, Eq. (17) becomes

$\mathbf{S}_{\mathrm{f}}=\frac{J_{\mathrm{c}} \lambda_{\mathrm{f}}}{2} \operatorname{Tr}\left(\boldsymbol{C}_{\mathrm{c}}^{-1} \frac{\mathrm{d} \mathbf{C}_{\mathrm{c}}}{\mathrm{d} t}\right) \boldsymbol{C}_{\mathrm{c}}^{-1}-J_{\mathrm{c}} \mu_{\mathrm{f}} \frac{\mathrm{d} \boldsymbol{C}_{\mathrm{c}}^{-1}}{\mathrm{~d} t}$

\subsection{The cell and its environment}

The cell reacts and interacts with its environment which is constituted of an underneath flat or micropillared substrate. In the following, we detail the different forces to which the cell is submitted and that affect its global behaviour.

\subsubsection{The underneath substrate}

The substrate may be flat or structured. In both cases, it is defined by a spatial characteristic function $g_{i}$ (where the subscript $i$ indicates the substrate type) which, as defined in Sect. 2.1, is a composition of a smooth Heaviside function $H$ and level set function $l_{i}$ which reads

$$
\begin{aligned}
g_{\text {flat }} & =H \circ l_{\text {flat }}=H \circ\left(-y+y_{\text {flat }}\right) \\
g_{\mathrm{mp}} & =H \circ l_{\mathrm{mp}}= \\
H \circ\left\{\left[\left|x-x_{\mathrm{mp}}-\left(s_{\mathrm{mp}}+w_{\mathrm{mp}}\right) \operatorname{round}\left(\frac{x-x_{\mathrm{mp}}}{s_{\mathrm{mp}}+w_{\mathrm{mp}}}\right)\right|^{4}\right.\right. & \\
& \left.\left.+\left|y-y_{\mathrm{mp}}\right|^{k_{\mathrm{mp}}}-\left(\frac{w_{\mathrm{mp}}}{2}\right)^{4}\right]+\mathrm{g}_{\mathrm{flat}}\right\}
\end{aligned}
$$


where the subscripts flat and $\mathrm{mp}$ indicate 'flat' and 'micropillared', respectively, and $x$ and $y$ are the coordinates of any particle in the system. The flat substrate $\mathrm{g}_{\text {flat }}$ is represented by a semi-infinite place at $y_{\text {flat }}$ position with respect to the $y$-axis. The micropillared substrate is represented by a series of pillars of width $w_{\mathrm{mp}}$, space of $s_{\mathrm{mp}}$ and height obtained through the coefficient $k_{\mathrm{mp}}$. We can consider an infinite number of pillars as a function of the first one which is positioned in $x_{\mathrm{mp}}$ and $y_{\mathrm{mp}}$. Finally, round is a function that rounds to the nearest integer.

For both $g_{\text {flat }}$ and $g_{\mathrm{mp}}$, we consider a thin layer covered with fibronectin and where the cell can therefore adhere. The layer is called $g_{\text {flat }, 1}$ and $g_{\mathrm{mp}, 1}$ for the flat and micropillared substrate, respectively, (Fig. 3). In the case of the flat substrate, the layer is obtained by subtracting $g_{\text {flat }}$ from a higher flat substrate (i.e. higher $y$ coordinate, $\left.y_{\text {flat, }, 1}>y_{\text {flat }}\right)$. In the case of the micropillared substrate, $g_{\mathrm{mp}}$ is subtracted from a wider (i.e. $w_{\mathrm{mp}, \mathrm{l}}>w_{\mathrm{mp}}$ ), higher (i.e. $h_{\mathrm{mp}, \mathrm{l}}>h_{\mathrm{mp}}$ thus $k_{\mathrm{mp}, \mathrm{l}}>k_{\mathrm{mp}}$ ) and with smaller inter-pillar space (i.e. $s_{\mathrm{mp}, 1}<s_{\mathrm{mp}}$ ) micropillared substrate (Fig. 3). In both cases, the thickness of the fibronectin layer $e_{\mathrm{f}}$ has been set to $1.5 \mu \mathrm{m}$. Such a value has been chosen assuming that although in reality the fibronectin thickness is in the order of some nanometres, the cell must 'sense' this adhering molecule at the microscale. From a numerical point of view, such a thickness, which is in the order of the mesh size, allows to precisely detect the adhesion between the cell and the fibronectin through the adhesion force $f_{\text {as }}$ (see Sect. 2.2.4).

The outward normal vectors $\boldsymbol{n}_{\mathrm{f}}$ and $\boldsymbol{n}_{\mathrm{mp}}$ (Fig. 3) to the flat and micropillared substrate, respectively, are given by

$\boldsymbol{n}_{\mathrm{f}}=\frac{\nabla_{x} l_{\text {flat }}}{\nabla_{x} l_{\text {flat }}}$ $\boldsymbol{n}_{\mathrm{mp}}=\frac{\nabla_{x} l_{\mathrm{mp}}}{\nabla_{x} l_{\mathrm{mp}}}$

\subsubsection{The gravity force}

At first, the cell is suspended and settles over the substrate due to the gravity $\boldsymbol{f}_{\mathrm{g}}$. Nevertheless, for numerical and convergence purposes, such a force cannot be applied all of a sudden but rather smoothly over a period of time $T_{\mathrm{g}}$. Then, it reads

$\boldsymbol{f}_{\mathrm{g}}=-\rho_{\mathrm{p}} t_{\mathrm{g}} \mathrm{g} \boldsymbol{i}_{y}$

with $\rho_{\mathrm{p}}$ being the initial cell density, $g$ the gravitational acceleration, and $\boldsymbol{i}_{y}$ the vertical unit vector. $t_{\mathrm{g}}$ is a temporal characteristic function which reads

$t_{\mathrm{g}}=H \circ l_{\mathrm{g}}=H \circ\left(-t+T_{\mathrm{g} 0}\right)$

with $t$ being the time and $T_{\mathrm{g} 0}$ the upper limit of $T_{\mathrm{g}}$ (Fig. 4).

Once the cell touches the substrate, the gravity is maintained, and two further forces start to act: the contact force $f_{\text {ct }}$ and the adhesive spreading force $f_{\text {as }}$.

\subsubsection{The contact force between the cell and the substrate}

The contact force $\boldsymbol{f}_{\mathrm{ct}}$ automatically applies once the cell approaches the substrate, whether it is flat or micropillared, over a very thin layer corresponding to the superposition between the cell and the substrate. Then, it is approximated by a volume force as proposed in our previous work (Deveraux et al. 2017).

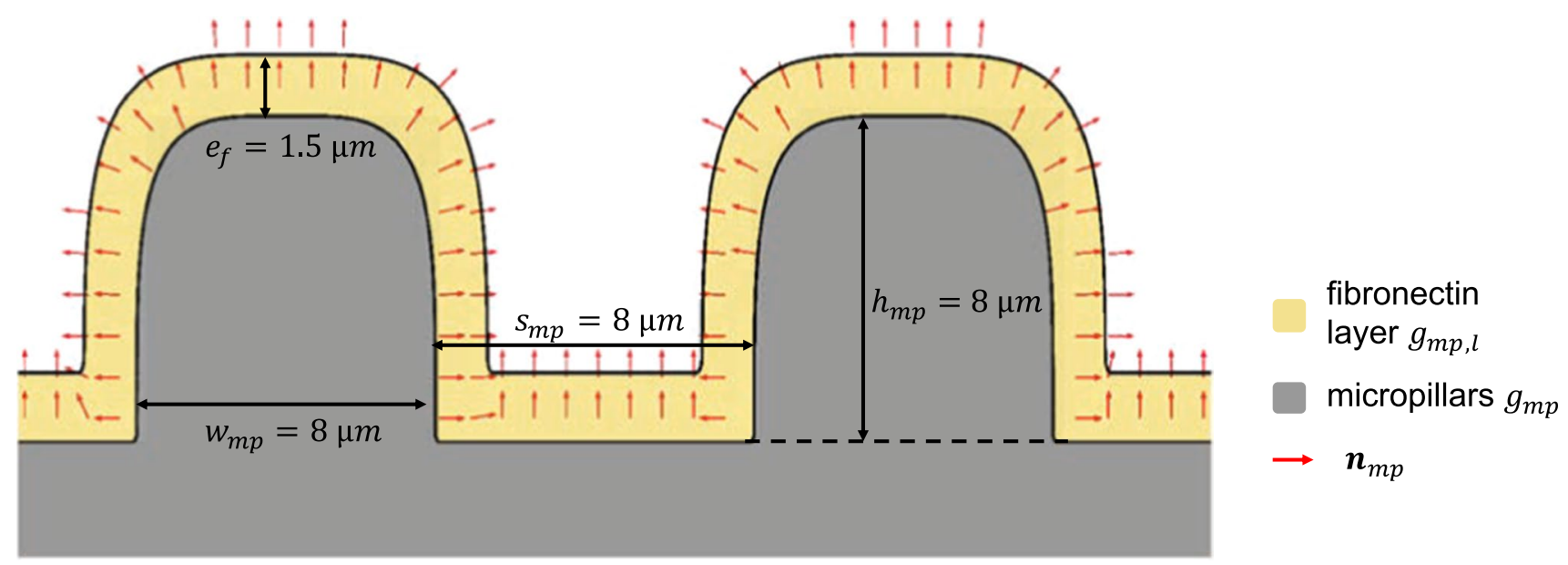

Fig. 3 Pillars $\left(g_{\mathrm{mp}}\right)$ in grey with the superposed layer of fibronectin $\left(g_{\mathrm{mp}, \mathrm{l}}\right)$ in yellow. The red arrows represent the outward normal vector $\boldsymbol{n}_{\mathrm{mp}}$. The dimensions of the pillars width $\left(w_{\mathrm{mp}}\right)$, height $\left(k_{\mathrm{mp}}\right)$ and interspace $\left(s_{\mathrm{mp}}\right)$ and of the fibronectin layer thickness $e_{\mathrm{f}}$ are also provided 


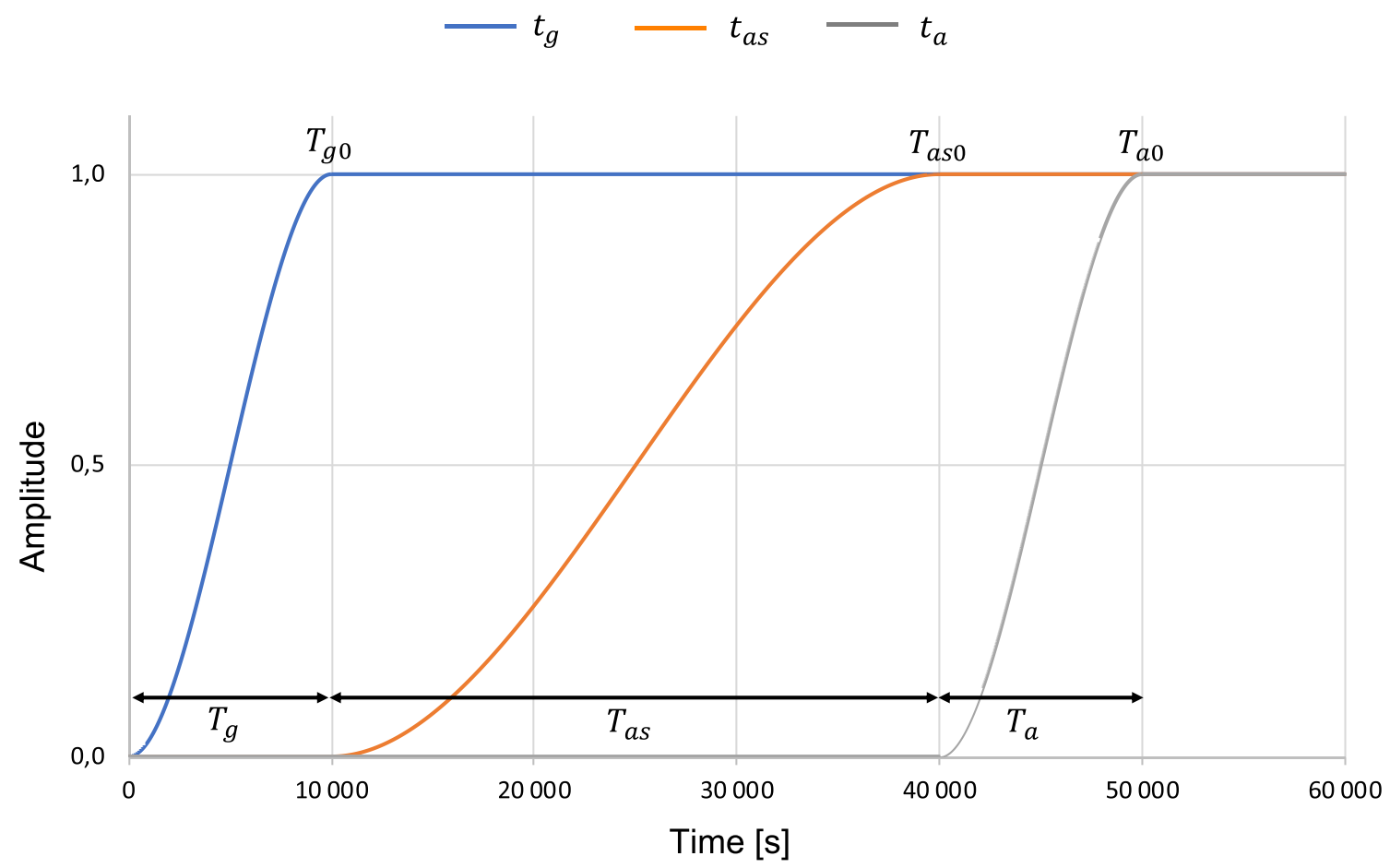

Fig. 4 Representation of the temporal characteristic functions necessary to describe the evolution of the gravity $\boldsymbol{f}_{\mathrm{g}}$ [i.e. the function $t_{\mathrm{g}}$ in blue, Eq. (24)], the adhesive spreading force $f_{\text {as }}$ [i.e. the function $t_{\text {as }}$ in orange, Eq. (27)] and the active strains $\boldsymbol{F}_{\mathrm{a}, \mathrm{PAC}}$ and $\boldsymbol{F}_{\text {a,bottom }}$ [i.e. the function $t_{\mathrm{a}}$ in grey, Eq. (35)]. Each function starts from 0 and reaches

We employ here a penalization technique via the level set functions $g_{\text {flat }}$ and $g_{\mathrm{mp}}$ which allow to measure the distance and the interpenetration between the cell and the substrates.

Then, $\boldsymbol{f}_{\mathrm{ct}}$ reads

$\boldsymbol{f}_{\mathrm{ct}}=\left\{\begin{array}{l}\mu_{\mathrm{ct}} g_{\mathrm{flat}} \operatorname{cof}\left(\boldsymbol{F}_{\mathrm{c}}\right) \boldsymbol{n}_{\text {flat }}, \text { on flat substrate } \\ \mu_{\mathrm{ct}} g_{\mathrm{mp}} \operatorname{cof}\left(\boldsymbol{F}_{\mathrm{c}}\right) \boldsymbol{n}_{\mathrm{mp}}, \text { on micropillared substrate }\end{array}\right.$

where $\mu_{\mathrm{ct}}$ is the penalization coefficient and the cofactor matrix is defined as $\operatorname{cof}\left(\boldsymbol{F}_{\mathrm{c}}\right)=J_{\mathrm{c}} \boldsymbol{F}_{\mathrm{c}}^{-\mathrm{T}}$. Since we employ here a Lagrangian description, the normal vectors $\boldsymbol{n}_{\text {flat }}$ and $\boldsymbol{n}_{\mathrm{mp}}$ must be brought back to their initial configuration by multiplying them by $\operatorname{cof}\left(\boldsymbol{F}_{\mathrm{c}}\right)$.

\subsubsection{The adhesive force}

The volume adhesive spreading force $\boldsymbol{f}_{\text {as }}$ allows to mimic the FAs maturation via the recruitment of scaffolding and signalling components (Geiger et al. 2009). When the cell gets closer to the substrate, the adhesive spreading force comes into action on the portions of the substrate coated with ECM proteins such as fibronectin. As in other works (Zeng and $\mathrm{Li}$ 2011a; Fan and Li 2015b; Fang and Lai 2016), we do not get into the molecular details of spreading, but design a single body force accounting for both the actin polymerization the maximum value 1 after a specific period of time: $T_{\mathrm{g}}=10,000 \mathrm{~s}$ for the gravity, $T_{\text {as }}=30,000 \mathrm{~s}$ for the adhesion spreading force and $T_{\mathrm{a}}=10,000 \mathrm{~s}$ for the active strains. The maximum value 1 is achieved at $T_{\mathrm{g} 0}, T_{\mathrm{as} 0}$ and $T_{\mathrm{a} 0}$, respectively

at the cell membrane (Keren 2011) and the formation of adhesion complexes between the cell and its environment (Fig. 5). This nonlinear force, attracting the cell towards the substrate, is one of the novelties of this model. Inspired by the work of Sauer (2016), we consider an overlayer of fibronectin surrounding the substrate, in which the spreading force will act on the cell's membrane. Our model only considers the case of a homogeneous fibronectin distribution over the substrate and thus a continuous overlayer.

$f_{\text {as }}$ is radial and is applied over a period $T_{\text {as }}$, starts at $t=T_{\mathrm{g} 0}$, reaches its maximum value at $t=T_{\text {as } 0}$ and is maintained afterwards (Fig. 4). The force is a body force, but it is applied at the thin intersection between the cell membrane and the fibronectin layer (Sect. 2.2.1). It reads

$\boldsymbol{f}_{\mathrm{as}}= \begin{cases}\mu_{\mathrm{as}}(\boldsymbol{x}, t) g_{\mathrm{f}, 1} g_{\mathrm{m}} t_{\mathrm{as}} \operatorname{cof}\left(\boldsymbol{F}_{\mathrm{c}}\right) \boldsymbol{n}_{\mathrm{c}, \mathrm{p}}, & \text { on flat substrate } \\ \mu_{\mathrm{as}}(\boldsymbol{x}, t) g_{\mathrm{mp}, 1} g_{\mathrm{m}} t_{\mathrm{as}} \operatorname{cof}\left(\boldsymbol{F}_{\mathrm{c}}\right) \boldsymbol{n}_{\mathrm{c}, \mathrm{p}}, & \text { on micropillared substrate }\end{cases}$

where $\operatorname{cof}\left(\boldsymbol{F}_{\mathrm{c}}\right) \boldsymbol{n}_{\mathrm{c}, \mathrm{p}}$ is the outward normal to the cell in the reference configuration. Such a normal is computed at the cell boundary, but it is easily extended inside the cell membrane through the gradient of membrane level set function $l_{\mathrm{m}} \cdot t_{\mathrm{as}}$ is a temporal characteristic function defined as

$t_{\mathrm{as}}=H \circ l_{\mathrm{as}}=H \circ\left[\left(t+T_{\mathrm{g} 0}\right)\left(-t+T_{\mathrm{as} 0}\right)\right]$ 
with $T_{\text {as } 0}$ being the upper limit of $t_{\text {as }}$ (Fig. 4).

$\mu_{\mathrm{as}}(\boldsymbol{x}, t)$ is the spreading coefficient which satisfies the following partial differential equation

$\frac{\partial \mu_{\mathrm{as}}(\boldsymbol{x}, t)}{\partial t}= \begin{cases}\mu_{\mathrm{as} 0} g_{\mathrm{f}, \text { layer }} g_{\mathrm{m}}, & \mu_{\mathrm{as}}(\boldsymbol{x}, t)<\mu_{\mathrm{as}, \max } \\ \mu_{\mathrm{as} 0} g_{\mathrm{mp}, \text { layer }} g_{\mathrm{m}}, & \mu_{\mathrm{as}}(\boldsymbol{x}, t)<\mu_{\mathrm{as}, \max } \\ 0, & \text { otherwise }\end{cases}$

where $\mu_{\mathrm{as} 0}$ and $\mu_{\mathrm{as}, \max }$ are the two positive scalars. Through this partial differential equation, $\mu_{\mathrm{as}}(\boldsymbol{x}, t)$ starts to smoothly increase as soon as the cell touches the substrate until it reaches a maximum value $\mu_{\mathrm{as}, \max }$. Equation (28) allows to mimic the FAs maturation via the recruitment of scaffolding and signalling components (Geiger et al. 2009).

\subsubsection{The active strains}

Once the cell has settled on the substrate due to the gravity $\boldsymbol{f}_{\mathrm{g}}$, spread and adhered on the micropillars due to $\boldsymbol{f}_{\mathrm{as}}$, it starts to actively deform. In fact, during spreading, intense contractile actin fibres have been observed at two locations in the cell: above the nucleus and around the pillars beneath the nucleus

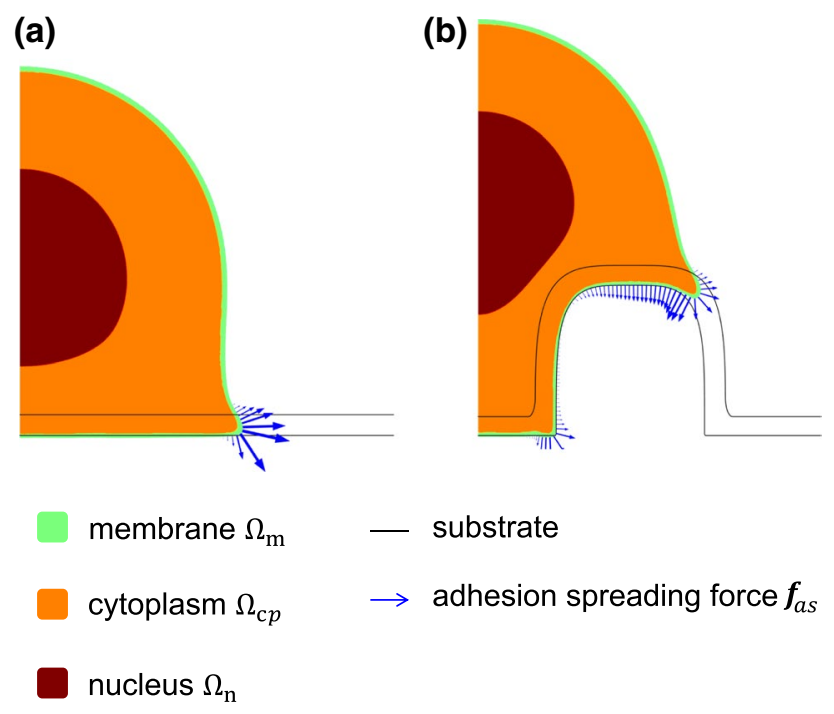

Fig. 5 Blue arrows indicate the adhesion spreading force $f_{\text {as }}$ in the case of a flat (a) and a micropillared (b) substrate (green $=$ membrane, orange $=$ cytoplasm, red $=$ nucleus) at $t=40,000 \mathrm{~s}$. The black lines represent the substrate and the fibronectin layer

(Hanson et al. 2015; Davidson et al. 2015). The active mechanism of cell spreading on a microstructured substrate is not well understood. A dome-like actin cap (i.e. the PAC) has been observed above the nucleus, as well as concentration of fibres around the pillars where the cell adheres. Therefore, we consider here two main regions where active strains may occur: $\Omega_{\text {PAC }}$ on top of the nucleus where the filaments are tangentially oriented and $\Omega_{\text {bottom }}$ below the nucleus where the actin filaments are radially oriented (see Fig. 1b). Both regions are described by two characteristic functions which read

$g_{\mathrm{PAC}}=H \circ l_{\mathrm{PAC}} \quad$ for $\theta \geq \theta_{\mathrm{PAC}}$

$g_{\text {bottom }}=g_{\text {cl }}$ for $\theta \leq \theta_{\text {bottom }}$

where $\theta=\operatorname{arctg}\left(\frac{y-c_{y}}{x-c_{x}}\right), \theta_{\mathrm{PAC}}$ and $\theta_{\text {bottom }}$ are two scalars and $l_{\text {PAC }}$ is the difference between two level set functions describing two ellipses (i.e. an external and an internal one) as follows:

$$
\begin{aligned}
l_{\mathrm{PAC}}= & {\left[-\left(\frac{x-c_{x, \boldsymbol{p}}}{a_{\mathrm{PAC}, \mathrm{ext}}}\right)^{2}-\left(\frac{y-c_{y, \boldsymbol{p}}}{b_{\mathrm{PAC}, \mathrm{ext}}}\right)^{2}+1\right] } \\
& -\left[-\left(\frac{x-c_{x, \boldsymbol{p}}}{a_{\mathrm{PAC}, \text { int }}}\right)^{2}-\left(\frac{y-c_{y, \boldsymbol{p}}}{b_{\mathrm{PAC}, \mathrm{int}}}\right)^{2}+1\right]
\end{aligned}
$$

with $a_{\mathrm{PAC}, \mathrm{ext}}, a_{\mathrm{PAC}, \text { int }}$ and $b_{\mathrm{PAC}, \mathrm{ext}}, b_{\mathrm{PAC}, \text { int }}$ being the major and minor axes of the ellipses, respectively.

According to the previous remarks, the active strain tensor $\boldsymbol{F}_{\mathrm{a}}$ is expressed

$\boldsymbol{F}_{\mathrm{a}}=\boldsymbol{I}+\boldsymbol{F}_{\mathrm{a}, \mathrm{PAC}}+\boldsymbol{F}_{\text {a,bottom }}$

with

$\boldsymbol{F}_{\mathrm{a}, \mathrm{PAC}}=g_{\mathrm{PAC}} e_{\mathrm{PAC}} t_{\mathrm{a}}\left(\operatorname{cof}\left(\boldsymbol{F}_{\mathrm{c}}\right) \boldsymbol{i}_{\mathrm{t}, \mathrm{PAC}} \otimes \operatorname{cof}\left(\boldsymbol{F}_{\mathrm{c}}\right) \boldsymbol{i}_{\mathrm{t}, \mathrm{PAC}}\right)$

$\boldsymbol{F}_{\text {a,bottom }}=g_{\text {bottom }} e_{\text {bottom }} t_{\mathrm{a}}\left(\operatorname{cof}\left(\boldsymbol{F}_{\mathrm{c}}\right) \boldsymbol{n}_{\mathrm{c}, \mathrm{p}} \otimes \operatorname{cof}\left(\boldsymbol{F}_{\mathrm{c}}\right) \boldsymbol{n}_{\mathrm{c}, \mathrm{p}}\right)$

where $e_{\mathrm{PAC}}$ and $e_{\mathrm{bottom}}$ are the intensities of the active strains as a function of time, $\operatorname{cof}\left(\boldsymbol{F}_{\mathrm{c}}\right) \boldsymbol{i}_{\mathrm{t}, \mathrm{PAC}}$ and $\operatorname{cof}\left(\boldsymbol{F}_{\mathrm{c}}\right) \boldsymbol{n}_{\mathrm{c}, \mathrm{p}}$ are the tangent vector to the $\Omega_{\text {PAC }}$ domain and the outward normal vector of the cell, respectively, in the initial configuration. $\otimes$ indicates the tensorial product, and $t_{\mathrm{a}}$ is a temporal characteristic function which reads

$t_{\mathrm{a}}=H \circ l_{\mathrm{a}}=h \circ\left[\left(t+T_{\mathrm{as} 0}\right)\left(-t+T_{\mathrm{a} 0}\right)\right]$

with $T_{\mathrm{a} 0}$ being a constant. It allows to start applying the active strain at $t=T_{\mathrm{as} 0}$ until its maximum value at $T_{\mathrm{a} 0}$ (Fig. 4). The active strain is smoothly applied over a period of time $T_{\mathrm{a}}$ and starts at $t=T_{\mathrm{s} 0}$. It has to be noticed that $\boldsymbol{F}_{\mathrm{a}}$ is applied in the two active regions (i.e. $g_{\text {PAC }}$ and $g_{\text {bottom }}$ ), whereas $\boldsymbol{F}_{\mathrm{a}}=\boldsymbol{I}$ elsewhere.

\subsection{Numerical implementation}

The global equilibrium of the system in the large strains theory reads

$\operatorname{Div}_{\mathrm{p}}\left(\boldsymbol{F}_{\mathrm{c}} \boldsymbol{S}_{\mathrm{c}}\right)+J_{\mathrm{c}} \boldsymbol{f}_{\mathrm{v}}=\rho_{\mathrm{p}} \boldsymbol{a}$

with Div being the divergence operator, $\boldsymbol{p}$ the initial configuration of any particle of the system, $f_{\mathrm{v}}$ the volume forces 
(i.e. the gravity $f_{\mathrm{g}}$ and the adhesive spreading force $\boldsymbol{f}_{\mathrm{as}}$ ) and $\boldsymbol{a}$ the acceleration.

To get the displacement field $\boldsymbol{u}$, we use a classical finite elements approximation and by multiplying each term of Eq. (36) by the kinematically admissible displacement test function $w$ and integrating over $\Omega_{c, p}$, the associated weak form is obtained expressed as follows:

$$
\int_{\Omega_{\mathrm{c}, \mathrm{p}}}\left(\operatorname{Div}_{\mathrm{p}}\left(\boldsymbol{F}_{\mathrm{c}} \boldsymbol{S}_{\mathrm{c}}\right), \boldsymbol{w}\right) \mathrm{d} V_{\mathrm{p}}+\int_{\Omega_{\mathrm{c}, \mathrm{p}}}\left(\rho_{\mathrm{p}} \boldsymbol{g}+J_{\mathrm{g}} \boldsymbol{f}_{\mathrm{as}}-\rho_{\mathrm{p}} \boldsymbol{a}, \boldsymbol{w}\right) \mathrm{d} V_{\mathrm{p}}=0
$$

with $(\boldsymbol{a}, \boldsymbol{b})$ being the Cartesian dot product between two vectors $\boldsymbol{a}$ and $\boldsymbol{b}$.

Through some algebraic operations and by applying the Stokes theorem, we obtain

$$
\begin{aligned}
& -\int_{\Omega_{\mathrm{c}, \mathrm{p}}} \operatorname{Tr}\left[\boldsymbol{F}_{\mathrm{c}} \boldsymbol{S}_{\mathrm{c}}\left(\boldsymbol{D}_{\mathrm{p}} \boldsymbol{w}\right)^{\mathrm{T}}\right] \mathrm{d} V_{\mathrm{p}}+\int_{\partial \Omega_{\mathrm{c}, \mathrm{p}}}\left(\boldsymbol{w}, \boldsymbol{F}_{\mathrm{c}} \boldsymbol{S}_{\mathrm{c}}\left(\boldsymbol{n}_{\mathrm{c}, \mathrm{p}}\right)\right) \mathrm{d} S_{\mathrm{p}} \\
& +\int_{\Omega_{\mathrm{c}, \mathrm{p}}}\left(\rho_{\mathrm{p}} \boldsymbol{g}+J_{\mathrm{c}} \boldsymbol{f}_{\mathrm{as}}-\rho_{\mathrm{p}} \boldsymbol{a}, \boldsymbol{w}\right) \mathrm{d} V_{\mathrm{p}}=0
\end{aligned}
$$

where the first and the third terms describe the internal stress in the cell and the volume forces applied to the cell, respectively. The boundary conditions on the cell surface with respect to the initial configuration read

$$
\boldsymbol{F}_{\mathrm{c}} \boldsymbol{S}_{\mathrm{c}} \boldsymbol{n}_{\mathrm{c}, \mathrm{p}} \mathrm{d} S_{\mathrm{p}}=\boldsymbol{f}_{\mathrm{s}, \mathrm{p}} \mathrm{d} S_{\mathrm{p}}
$$

where $f_{\mathrm{s}, \mathrm{p}}$ stands for the surface forces applied to the cell.

Then, Eq. (38) becomes

$$
\begin{aligned}
& -\int_{\Omega_{c, p}} \operatorname{Tr}\left[\boldsymbol{F}_{\mathrm{c}} \boldsymbol{S}_{\mathrm{c}}\left(\boldsymbol{D}_{\mathrm{p}} \boldsymbol{w}\right)^{\mathrm{T}}\right] \mathrm{d} V_{\mathrm{p}}+\int_{\partial \Omega_{\mathrm{c}, \mathrm{p}}}\left(\boldsymbol{w}, \boldsymbol{f}_{\mathrm{s}, \mathrm{p}}\right) \mathrm{d} S_{\mathrm{p}} \\
& +\int_{\Omega_{\mathrm{c}, \mathrm{p}}}\left(\rho_{\mathrm{p}} \boldsymbol{g}+J_{\mathrm{c}} \boldsymbol{f}_{\mathrm{as}}-\rho_{\mathrm{p}} \boldsymbol{a}, \boldsymbol{w}\right) \mathrm{d} V_{\mathrm{p}}=0
\end{aligned}
$$

As previously mentioned (Sect. 2.2.3), the contact force $f_{\mathrm{ct}}$ is approximated by a volume force over a very thin layer (Deveraux et al. 2017). In fact, by similarity with shell theory, the surface integral in Eq. (40) can be written as a volume integral over the thickness $h_{\mathrm{p}}$ of the penalization depth of the contact. Thus, we have

$$
\begin{aligned}
& -\int_{\Omega_{\mathrm{c}, \mathrm{p}}} \operatorname{Tr}\left[\boldsymbol{F}_{\mathrm{c}} \boldsymbol{S}_{\mathrm{c}}\left(\boldsymbol{D}_{\mathrm{p}} \boldsymbol{w}\right)^{\mathrm{T}}\right] \mathrm{d} V_{\mathrm{p}} \\
& \quad+\int_{\Omega_{\mathrm{c}, \mathrm{p}}}\left(\rho_{\mathrm{p}} \boldsymbol{g}+\boldsymbol{f}_{\mathrm{s} \rightarrow \mathrm{v}}+J_{\mathrm{c}} \boldsymbol{f}_{\mathrm{as}}-\rho_{\mathrm{p}} \boldsymbol{a}, \boldsymbol{w}\right) \mathrm{d} V_{\mathrm{p}}=0
\end{aligned}
$$

where $f_{\mathrm{s} \rightarrow \mathrm{v}}=h_{\mathrm{p}} f_{\mathrm{s}, \mathrm{p}}=h_{\mathrm{p}} f_{\mathrm{ct}}$.
To solve the problem, Eq. (41) is directly implemented in the weak form in COMSOL Multiphysics $\odot$ and discretized both in time and in space. The discretization in space is achieved through quadratic polynomials inside each isoparametric element of the mesh. The initial mesh elements have a size between $0.3 \mu \mathrm{m}$ (at the lower edge of the cell) and $1 \mu \mathrm{m}$ in the nucleus. For the discretization in time, we use a second-order backward differentiation formula (BDF). In order to compute the solution, we use a nonlinear Newton method as our iterative algorithm with a relative tolerance of $1 \%$ and maximum number of iterations equal to 300 .

\section{Results}

In this section, we present the main results of our numerical simulations. The parameters of the model are listed in Table 1. Some of these parameters have been tuned to reproduce the experiments of interest, while others, such as the mechanical properties of the cell and the nucleus, have been taken from the literature but can of course be modified since they may affect the global cellular response.

\subsection{Cell spreading on flat substrate}

First, we validate our approach by comparing the numerical results obtained for cell spreading on flat substrate with the existing literature. In this simulation, we only consider the action of the gravity, the spreading adhesive force and the contact force. The cell is initially positioned in the adhesive layer of fibronectin, but still suspended. $f_{\mathrm{g}}$ and $f_{\text {as }}$ are smoothly applied, and thus, they reach their maximum values at $T_{\mathrm{g} 0}=10,000 \mathrm{~s}$ and $T_{\mathrm{as} 0}=40,000 \mathrm{~s}$. As soon as the cell enters in contact with the substrate, $f_{\text {ct }}$ applies too (Fig. 6a). In Fig. 6b, the evolution of the contact radius (i.e. the length of the cell contour in contact with the substrate) between the cell and the flat substrate is plotted. Gravity slightly increases the contact surface up to $1 \mu \mathrm{m}$. When the spreading process begins, however, we observe a much faster spreading with a maximum contact radius of $8.8 \mu \mathrm{m}$. This is in agreement with the experimental results presented in Cuvelier et al. (2007). The authors were able to quantify cell spreading employing reflection interference contrast microscopy (RICM) and monitoring the contact between the cell membrane and underneath surface.

\subsection{Nucleus and cytoplasm deformation on micropillared substrate}

The second series of simulations aims at reproducing specific experimental tests for which suspended cells are plated on an array of microfabricated pillars. The objective here is to analyse the nucleus and cytoplasm deformation once 
Table 1 Main parameters of the model

\begin{tabular}{|c|c|c|c|}
\hline Parameter & Description & Value & References \\
\hline$c_{x, p}$ & $x$ position of the cell centre in the initial configuration & $0 \mu \mathrm{m}$ & \\
\hline$c_{y, p}$ & $y$ position of the cell centre in the initial configuration & $8.5 \mu \mathrm{m}$ & \\
\hline$r_{\mathrm{c}}$ & Cell radius & $10 \mu \mathrm{m}$ & \\
\hline$r_{\mathrm{cs}}$ & Cytosol radius & $9.75 \mu \mathrm{m}$ & \\
\hline$r_{\mathrm{n}}$ & Nucleus radius & $5 \mu \mathrm{m}$ & \\
\hline$e_{\mathrm{cs}}$ & Cytosol thickness & $4.75 \mu \mathrm{m}$ & \\
\hline$e_{\mathrm{m}}$ & Membrane thickness & $0.25 \mu \mathrm{m}$ & \\
\hline$e_{\mathrm{f}}$ & Fibronectin layer thickness & $1.5 \mu \mathrm{m}$ & \\
\hline$E_{\mathrm{cp}}$ & Cytoplasm Young's modulus & $100 \mathrm{~Pa}$ & Caille et al. (2002) \\
\hline$E_{\mathrm{n}}$ & Nucleus Young's modulus & $500 \mathrm{~Pa}$ & Fried and Johnson (1988) \\
\hline$v_{\mathrm{c}}$ & Cell's Poisson ratio & 0.485 & \\
\hline$\rho_{\mathrm{cp}}$ & Cytoplasm density & $1000 \mathrm{~kg} / \mathrm{m}^{3}$ & Fried and Johnson (1988) \\
\hline$\rho_{\mathrm{n}}$ & Nucleus density & $1400 \mathrm{~kg} / \mathrm{m}^{3}$ & Fried and Johnson (1988) \\
\hline$\mu_{\mathrm{f}}$ & Deviatoric viscosity & $\begin{array}{l}2 \times \\
10^{-3} \mathrm{~Pa} \mathrm{~s}\end{array}$ & \\
\hline$\lambda_{\mathrm{f}}$ & Isotropic viscosity & $1000 \mathrm{~Pa} \mathrm{~s}$ & \\
\hline$y_{\text {flat }}$ & $y$ position of the flat substrate & $-2 \mu \mathrm{m}$ & \\
\hline$y_{\text {flat }, 1}$ & $y$ position of the overlayer flat substrate & $-6 \mu \mathrm{m}$ & \\
\hline$x_{m p}$ & $x$ position for the centre of the first pillar & $8 \mu \mathrm{m}$ & \\
\hline$y_{\mathrm{mp}}$ & $y$ position for the centre of the first pillar & $-8 \mu \mathrm{m}$ & \\
\hline$k_{\mathrm{mp}}$ & Pillars coefficient & 4.2 & \\
\hline$w_{\mathrm{mp}}$ & Pillars width & $8 \mu \mathrm{m}$ & \\
\hline$s_{\mathrm{mp}}$ & Inter-pillars space & $8 \mu \mathrm{m}$ & \\
\hline$k_{\mathrm{mp}, 1}$ & Overlayer pillars coefficient & 4.24 & \\
\hline$w_{\mathrm{mp}, 1}$ & Overlayer pillars width & $10 \mu \mathrm{m}$ & \\
\hline$s_{\mathrm{mp}, 1}$ & Overlayer inter-pillars space & $8 \mu \mathrm{m}$ & \\
\hline$T_{\mathrm{g}}$ & Duration of the gravity phase & $10,000 \mathrm{~s}$ & \\
\hline$T_{\mathrm{g} 0}$ & Upper limit of $T_{\mathrm{g}}$ & $10,000 \mathrm{~s}$ & \\
\hline$\mu_{\mathrm{ct}}$ & Contact coefficient & $2 \times 10^{9} \mathrm{~N}$ & \\
\hline$T_{\text {as }}$ & Duration of the adhesive spreading phase & $30,000 \mathrm{~s}$ & \\
\hline$T_{\text {as } 0}$ & Upper limit of $T_{\text {as }}$ & $40,000 \mathrm{~s}$ & \\
\hline$\mu_{\mathrm{as} 0}$ & Focal adhesions maturation velocity & $1 \times 10^{6} \mathrm{~N} / \mathrm{s}$ & \\
\hline$\mu_{\text {as, } \max }$ & Maximum spreading coefficient & $1.4 \times 10^{9} \mathrm{~N}$ & \\
\hline$T_{\mathrm{a}}$ & Duration of the active strain phase & $10,000 \mathrm{~s}$ & \\
\hline$T_{\mathrm{a} 0}$ & Upper limit of $T_{a}$ & $50,000 \mathrm{~s}$ & \\
\hline$\theta_{\mathrm{PAC}}$ & Defining angle for the PAC domain & $-18^{\circ}$ & \\
\hline$\theta_{\text {bottom }}$ & Defining angle for the bottom domain & $-35^{\circ}$ & \\
\hline$a_{\mathrm{PAC}, \mathrm{ext}}$ & External first semi-axis of the PAC domain & $10 \mu \mathrm{m}$ & \\
\hline$b_{\mathrm{PAC}, \mathrm{ext}}$ & Internal first semi-axis of the PAC domain & $9 \mu \mathrm{m}$ & \\
\hline$a_{\mathrm{PAC}, \text { int }}$ & External second semi-axis of the PAC domain & $15 \mu \mathrm{m}$ & \\
\hline$b_{\mathrm{PAC} \text {,int }}$ & Internal second semi-axis of the PAC domain & $14 \mu \mathrm{m}$ & \\
\hline$e_{\mathrm{PAC}}$ & Amplitude of active strain in the PAC domain & 0.7 & \\
\hline$e_{\text {bottom }}$ & Amplitude of active strain in the bottom domain & 0.7 & \\
\hline
\end{tabular}

the interaction between the cell and the micropillars starts and more specifically to decipher which mechanical forces play the major role and trigger the nucleus large strains. As explained in Sect. 1, the cell first settles on the pillars due to the gravity, second it slowly spreads and adheres on them, and finally it actively deforms. This final phase may occur on the top (i.e. PAC region) or beneath (i.e. bottom region) the nucleus. Through these simulations, we would like to understand which of these two active strains is more relevant and promotes the nucleus self-deformation between the pillars. 
(a)

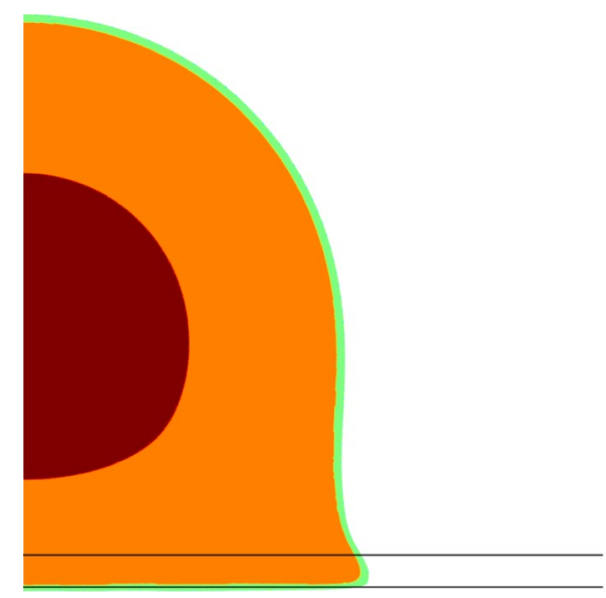

membrane $\Omega_{\mathrm{m}}$

nucleus $\Omega_{\mathrm{n}}$

cytoplasm $\Omega_{\mathrm{c} p}$ (b)

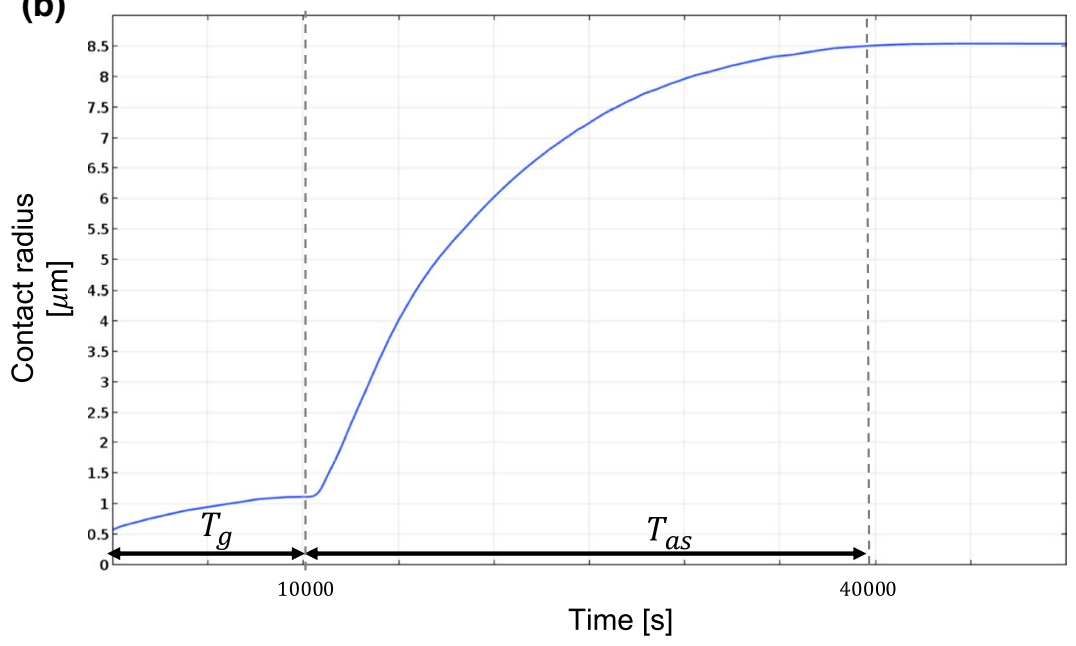

- substrate

Fig. 6 a Cell spreading over a flat substrate at $t=40,000 \mathrm{~s}$. b Evolution of the contact radius with respect to time between $t=0 \mathrm{~s}$, when the gravity is applied, and $t=40,000 \mathrm{~s}$ when the adhesion spreading force $f_{\text {as }}$ reaches its maximum value

The pillars have height $k_{\mathrm{mp}}=8 \mu \mathrm{m}$ and width $w_{\mathrm{mp}}=8 \mu \mathrm{m}$ and are spaced of $s_{\mathrm{mp}}=8 \mu \mathrm{m}$.

In Fig. 7, the average norm of the Lagrangian deformation tensor in the nucleus (Fig. 7a-c) and in the cytoplasm (Fig. 7d-f) is shown for the three scenarios: (1) 'push' active strain (Fig. 7a, c), (2) 'pull' active strain (Fig. 7b, e) and 'push-pull' active strain (Fig. 7c, f). For the nucleus, it is possible to notice that the strain is higher for the 'pull' and 'push-pull' configurations, with an average value of $37 \%$. However, for the 'push' scenario, the nucleus only deforms of about $13 \%$. For the cytoplasm, larger strains are achieved, especially in the region around the pillar. The cytoplasm average norm of the Lagrangian deformation tensor increases from the 'push' configuration $(56 \%)$ to the 'pull' (59\%) and 'push-pull' (69\%) configurations. In all the simulations, very large strains are observed as expected. Such an outcome completely justifies the choice of the parameters of the Yeoh material model. In fact, according to the experimental data presented in Erk et al. (2010) and Storm et al. (2005), the Young modulus of the actin fibres exponentially increases as a function of the strain. If this was the case here, the raising of the stiffening phenomenon would inhibit the cell penetration in between the pillars and we would not obtain the nucleus self-deformation as it has been experimentally observed (Morgan et al. 2007; Geiger et al. 2009; Liu et al. 2017, 2018). Thus, as explained in Sect. 2.1.1, the parameters $\alpha_{2}$ and $\alpha_{3}$ associated with the Yeoh visco-hyperelastic material and describing the stiffening mechanism have been kept low in our numerical model. Doing so allows to take into account the strain stiffening as described in Erk et al. (2010) and Storm et al. (2005) for strains lower than 10\%, but to consider a slower increase in the cell stiffness for strains higher than $10 \%$.

In all cases, gravity seems having little effect on the global nucleus displacement which is equal to $0.1 \mu \mathrm{m}$ at $T_{\mathrm{g} 0}$. During the spreading phase (i.e. between $T_{\mathrm{g} 0}$ and $T_{\mathrm{as} 0}$ ), the nucleus gets positioned at the beginning of the gap but is not fully engaged yet and the displacement is equal to $5 \mu \mathrm{m}$. During the active strain phase (i.e. between $T_{\mathrm{as} 0}$ and $T_{\mathrm{a} 0}$ ), different behaviours are observed:

- If only the PAC actively deforms (i.e. 'push' active strain, Fig. 8a-c, Movie 1), the maximum displacement of the nucleus is equal to $5.4 \mu \mathrm{m}$ which corresponds to the least efficient scenario;

- If only the region beneath the nucleus deforms (i.e. 'pull' active strain, Fig. 8d-f, Movie 2) or if both the push and the pull forces are applied (i.e. 'push-pull' active strain, Fig. $8 \mathrm{~g}-\mathrm{i}$, Movie 3), then the nucleus reaches $9.6 \mu \mathrm{m}$ of displacement. Nonetheless, a slight difference can be noticed between the two cases since the combined active strains provide a nucleus displacement of $9.65 \mu \mathrm{m}$ versus 9.63 for the pull case. 
(a)

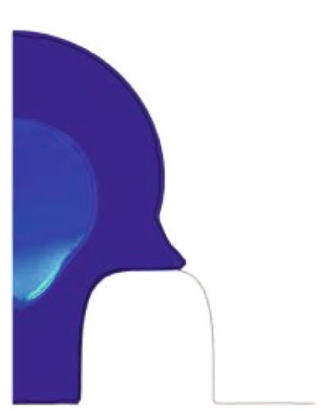

(d)

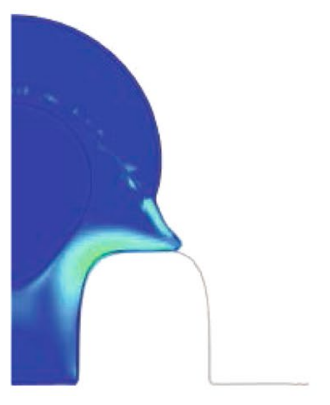

(b)

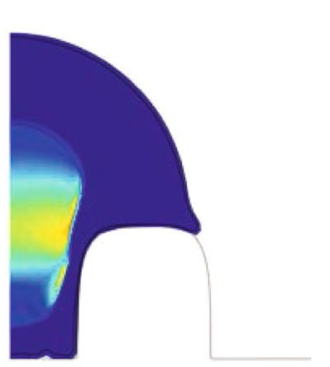

(e)

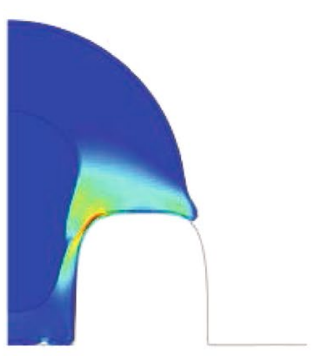

(c)

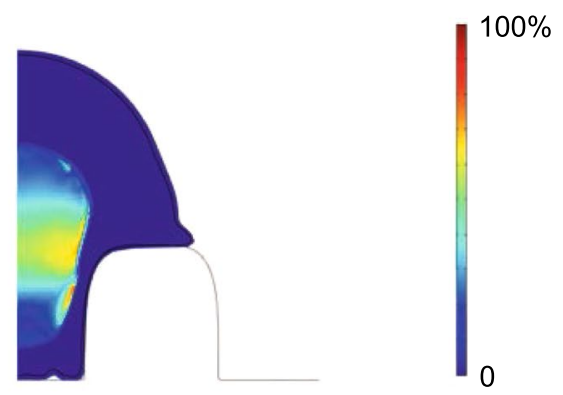

(f)

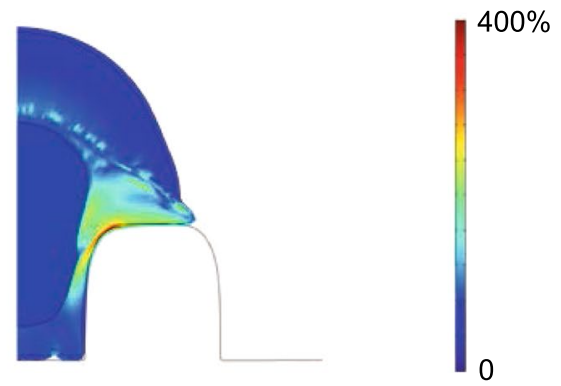

Fig. 7 a-c Average norm of the Lagrangian deformation tensor for the nucleus for the 'push' (a), 'pull' (b) and 'push-pull' configurations. d-f Average norm of the Lagrangian deformation tensor for the cytoplasm for the 'push' (a), 'pull' (b) and 'push-pull' configurations

Fig. 8 Graphical representation of the numerical results for 'push' active strain $(\mathbf{a}-\mathbf{c})$, 'pull' active strain (d-f) and 'push-pull' active strain $(\mathbf{g}-\mathbf{i})($ green $=$ membrane, orange $=$ cytoplasm, red $=$ nucleus). The black lines represent the substrate and the fibronectin layer, while the blue line represents the active domain considered (a)

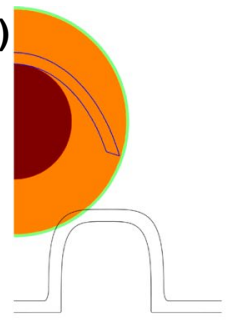

(d)

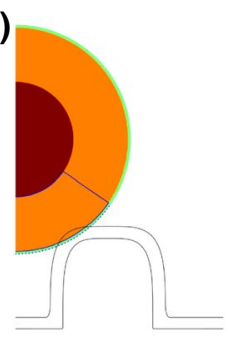

(g)

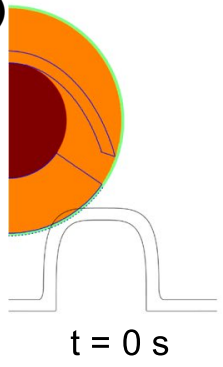

(b)

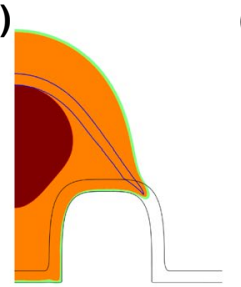

(e)

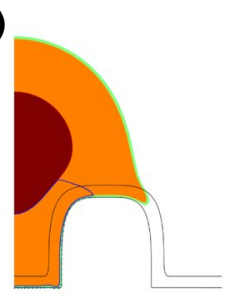

(h)

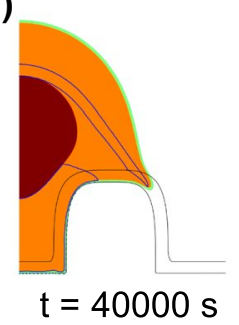

(c)

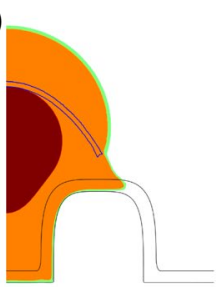

(f)

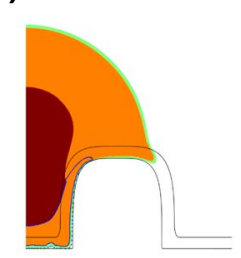

(i)

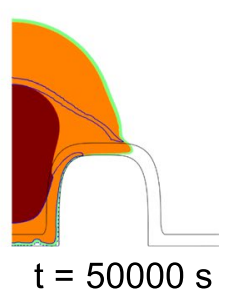

membrane $\Omega_{\mathrm{m}}$

nucleus $\Omega_{\mathrm{n}}$

cytoplasm $\Omega_{\mathrm{c} p}$

- substrate

- active domain 


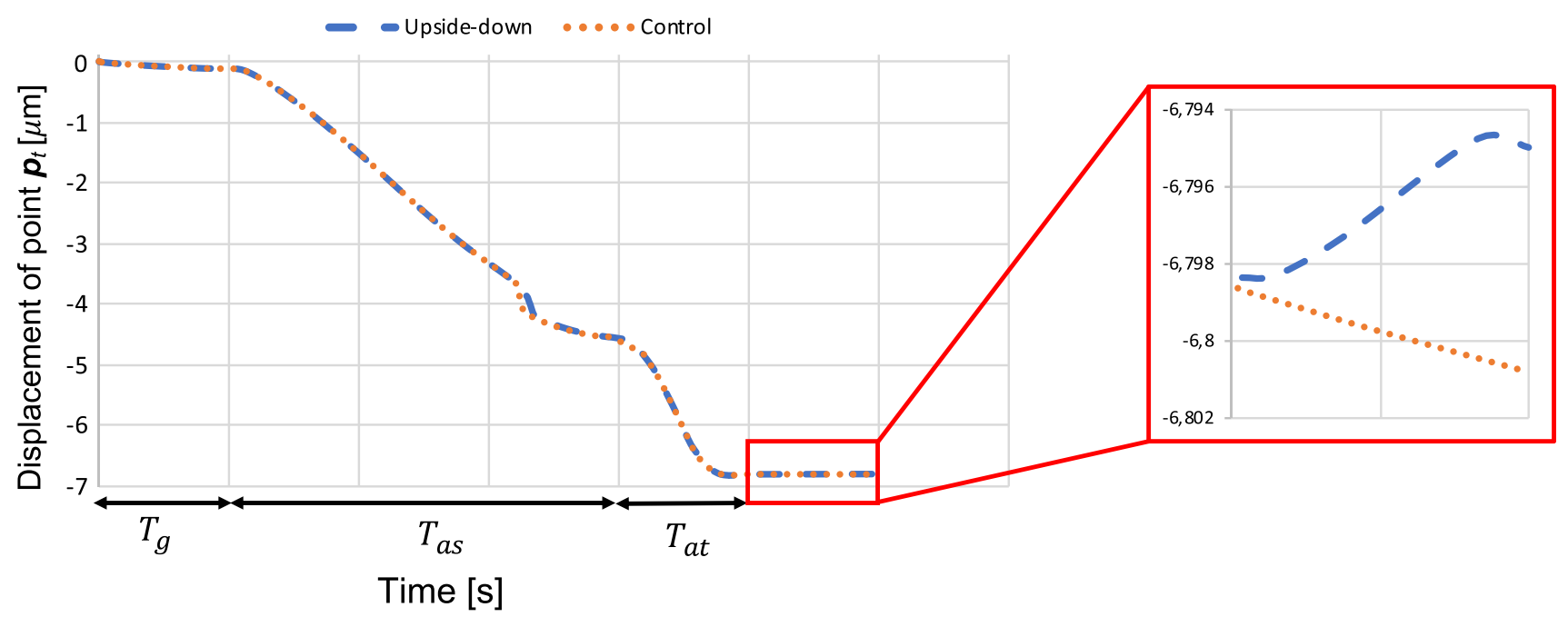

Fig. 9 Displacement over time of the point $\boldsymbol{p}_{\mathrm{t}}$ (see Fig. 1b) for the control (dotted red line) and the 'upside down' (dashed blue line) case

\subsection{The role of gravity}

According to the previous results, we can consider the "push and pull' case as the control simulation since it provides the best results in terms of nucleus total displacement. We would like now to investigate the role of the gravity on the global behaviour of the cell. Pan et al. (2012) have performed a specific test which consists in putting the micropillared device upside down once the cell has spread on top of the pillars, and the nucleus has fallen between the pillars. They observed that the nucleus was deformed as significantly as on the device not overturned. To reproduce such an experiment, we simply ran the simulation as in Sect. 3.2, but at the end (i.e. $t>T_{\mathrm{a} 0}$ ), we inverted the sign of the gravity force $\boldsymbol{F}_{\mathrm{g}}$. As it is possible to observe in Fig. 9, the effect of the gravity if negligible since only a difference of $0.006 \mu \mathrm{m}$ is obtained between the control case (red curve in Fig. 9) and the 'upside down' case (blue curve in Fig. 9).

\section{Conclusions}

We presented here a computational model to investigate the mechanisms triggering nucleus self-deformation during cell spreading over a microstructured substrate. We built a 2D FE model of half of a cell which is equipped with two active domains above (i.e. the PAC) and underneath the nucleus. At the initial configuration, the cell is suspended and gently comes into contact with the pillars due to the gravity. Then, it adheres on the pillars and starts spreading and actively deforming. We have been able to discern which active strain among the 'pushing' in the PAC domain and the 'pulling' in the bottom zone is the most relevant for the nucleus deformation. We found that PAC strain (i.e. 'push' active strain) has little influence on nucleus behaviour, while bottom strain (i.e. 'pull' active strain) alone is as efficient as the combination of both strains. Although in Hanson et al. (2015), by applying both 'push' and 'pull' forces, the nucleus was able to penetrate more deeply between the pillars, one may conclude that the nucleus is mostly pulled down by the actin filament that is radially distributed in the bottom region of the cell. We also tested the role of the gravity, and we confirmed that it has no significant impact on the nucleus strain as it has been experimentally observed by Pan et al. (2012). Our model, which includes some sophisticated mechanical tools (i.e. large strains, active strains and hyperelastic and viscous constitutive laws), appears to be consistent when compared to the available literature.

Nonetheless, some limitations may be drawn. First, we decided here to stick to a 2D representation for computing time reasons. However, a 3D representation of the system (i.e. both the cell and the microstructured substrate) would allow to more realistically catch the cellular strains and the adaptability of the cell and of the nucleus to their environment. Second, the successive phases of the model (i.e. gravity, adhesion, spreading and active strains) are 'user-controlled' since they start at specific time points of the simulation. One great advance would be to let these steps depend on one or more specific biophysical quantities (Allena et al. 2013) (i.e. molecules such as globular actin or myosin) so that the system would be autoregulated. Finally, we represented the cell as an isotropic continuum and we are currently working to implement an anisotropic material model in order to take into account the critical role of the actin fibres immersed in the cytoplasm and driving, through the polymerization-depolymerization processes, the overall cell deformation (Nolan et al. 2014). 
Acknowledgements This work was funded by a $\mathrm{PhD}$ fellowship of the French Government.

\section{References}

Abercrombie M, Heaysman JEM, Pegrum SM (1970) The locomotion of fibroblasts in culture I. Movements of the leading edge. Exp Cell Res 59:393-398. https://doi.org/10.1016/00144827(70)90646-4

Allena R, Aubry D (2012) "Run-and-tumble" or "look-and-run"? A mechanical model to explore the behavior of a migrating amoeboid cell. J Theor Biol 306:15-31. https://doi.org/10.1016/j. jtbi.2012.03.041

Allena R, Mouronval A-S, Aubry D (2010) Simulation of multiple morphogenetic movements in the Drosophila embryo by a single 3D finite element model. J Mech Behav Biomed Mater 3:313-323. https://doi.org/10.1016/j.jmbbm.2010.01.001

Allena R, Muñoz JJ, Aubry D (2013) Diffusion-reaction model for Drosophila embryo development. Comput Methods Biomech Biomed Eng 16:235-248. https://doi.org/10.1080/10255 842.2011.616944

Ambrosi D, Pezzuto S (2011) Active stress vs. active strain in mechanobiology: constitutive issues. J Elast 107:199-212. https://doi. org/10.1007/s10659-011-9351-4

Ambrosi D, Arioli G, Nobile F, Quarteroni A (2011) Electromechanical coupling in cardiac dynamics: the active strain approach. SIAM J Appl Math 71:605-621. https://doi.org/10.1137/100788379

Badique F, Stamov DR, Davidson PM et al (2013) Directing nuclear deformation on micropillared surfaces by substrate geometry and cytoskeleton organization. Biomaterials 34:2991-3001. https:// doi.org/10.1016/j.biomaterials.2013.01.018

Bao G, Suresh S (2003) Cell and molecular mechanics of biological materials. Nat Mater 2:715-725. https://doi.org/10.1038/nmat1 001

Bell ES, Lammerding J (2016) Causes and consequences of nuclear envelope alterations in tumour progression. Eur J Cell Biol 95:449-464. https://doi.org/10.1016/j.ejcb.2016.06.007

Benjamin M, Hillen B (2003) Mechanical influences on cells, tissues and organs-"Mechanical Morphogenesis". Eur J Morphol 41:37. https://doi.org/10.1076/ejom.41.1.3.28102

Bonet J, Gil AJ, Ortigosa R (2015) A computational framework for polyconvex large strain elasticity. Comput Methods Appl Mech Eng 283:1061-1094. https://doi.org/10.1016/j.cma.2014.10.002

Caille N, Thoumine O, Tardy Y, Meister J-J (2002) Contribution of the nucleus to the mechanical properties of endothelial cells. $\mathrm{J}$ Biomech 35:177-187

Cao X, Lin Y, Driscoll TP et al (2015) A chemomechanical model of matrix and nuclear rigidity regulation of focal adhesion size. Biophys J 109:1807-1817. https://doi.org/10.1016/j.bpj.2015.08.048

Cherubini C, Filippi S, Nardinocchi P, Teresi L (2008) An electromechanical model of cardiac tissue: constitutive issues and electrophysiological effects. Prog Biophys Mol Biol 97:562-573. https ://doi.org/10.1016/j.pbiomolbio.2008.02.001

Cuvelier D, Théry M, Chu Y-S et al (2007) The universal dynamics of cell spreading. Curr Biol 17:694-699. https://doi.org/10.1016/j. cub.2007.02.058

Davidson PM, Özçelik H, Hasirci V et al (2009) Microstructured surfaces cause severe but non-detrimental deformation of the cell nucleus. Adv Mater 21:3586-3590. https://doi.org/10.1002/ adma.200900582

Davidson PM, Fromigué O, Marie PJ et al (2010) Topographically induced self-deformation of the nuclei of cells: dependence on cell type and proposed mechanisms. J Mater Sci Mater Med 21:939946. https://doi.org/10.1007/s10856-009-3950-7

Davidson PM, Sliz J, Isermann P et al (2015) Design of a microfluidic device to quantify dynamic intra-nuclear deformation during cell migration through confining environments. Integr Biol Quant Biosci Nano Macro 7:1534-1546. https://doi.org/10.1039/c5ib0 0200a

Denais CM, Gilbert RM, Isermann P et al (2016) Nuclear envelope rupture and repair during cancer cell migration. Science 352:353358. https://doi.org/10.1126/science.aad7297

Deveraux S, Allena R, Aubry D (2017) A numerical model suggests the interplay between nuclear plasticity and stiffness during a perfusion assay. J Theor Biol. https://doi.org/10.1016/j. jtbi.2017.09.007

du Roure O, Saez A, Buguin A et al (2005) Force mapping in epithelial cell migration. Proc Natl Acad Sci 102:2390-2395. https://doi. org/10.1073/pnas.0408482102

Erk KA, Henderson KJ, Shull KR (2010) Strain stiffening in synthetic and biopolymer networks. Biomacromol 11:1358-1363. https:// doi.org/10.1021/bm100136y

Ermis M, Akkaynak D, Chen P et al (2016) A high throughput approach for analysis of cell nuclear deformability at single cell level. Sci Rep 6:36917. https://doi.org/10.1038/srep36917

Étienne J, Duperray A (2011) Initial dynamics of cell spreading are governed by dissipation in the actin cortex. Biophys J 101:611621. https://doi.org/10.1016/j.bpj.2011.06.030

Fan H, Li S (2015a) Modeling microtubule cytoskeleton via an active liquid crystal elastomer model. Comput Mater Sci 96:559-566. https://doi.org/10.1016/j.commatsci.2014.04.041

Fan H, Li S (2015b) Modeling universal dynamics of cell spreading on elastic substrates. Biomech Model Mechanobiol 14:1265-1280. https://doi.org/10.1007/s10237-015-0673-1

Fang Y, Lai KWC (2016) Modeling the mechanics of cells in the cell-spreading process driven by traction forces. Phys Rev E 93:042404. https://doi.org/10.1103/physreve.93.042404

Fried I, Johnson AR (1988) A note on elastic energy density functions for largely deformed compressible rubber solids. Comput Methods Appl Mech Eng 69:53-64. https://doi.org/10.1016/00457825(88)90166-1

Friedl P, Wolf K, Lammerding J (2011) Nuclear mechanics during cell migration. Curr Opin Cell Biol 23:55-64. https://doi. org/10.1016/j.ceb.2010.10.015

Geiger B, Spatz JP, Bershadsky AD (2009) Environmental sensing through focal adhesions. Nat Rev Mol Cell Biol 10:21-33. https ://doi.org/10.1038/nrm2593

Ghibaudo M, Di Meglio J-M, Hersen P, Ladoux B (2011) Mechanics of cell spreading within 3D-micropatterned environments. Lab Chip 11:805-812. https://doi.org/10.1039/c0lc00221f

Golestaneh AF, Nadler B (2016) Modeling of cell adhesion and deformation mediated by receptor-ligand interactions. Biomech Model Mechanobiol 15:371-387. https://doi.org/10.1007/s1023 7-015-0694-9

Hanson L, Zhao W, Lou H-Y et al (2015) Vertical nanopillars for in situ probing of nuclear mechanics in adherent cells. Nat Nanotechnol 10:554-562. https://doi.org/10.1038/nnano.2015.88

Holzapfel GA (2000) Nonlinear solid mechanics: a continuum approach for engineering, 1st edn. Wiley, Hoboken

Ingber DE (2003) Tensegrity I. Cell structure and hierarchical systems biology. J Cell Sci 116:1157-1173. https://doi.org/10.1242/ jcs.00359

Jean RP, Chen CS, Spector AA (2003) Analysis of the deformation of the nucleus as a result of alterations of the cell adhesion area, pp 121-122. https://doi.org/10.1115/imece2003-42905

Keren K (2011) Membrane tension leads the way. Proc Natl Acad Sci 108:14379-14380. https://doi.org/10.1073/pnas.1111671108 
Khatau SB, Hale CM, Stewart-Hutchinson PJ et al (2009) A perinuclear actin cap regulates nuclear shape. Proc Natl Acad Sci USA 106:19017-19022. https://doi.org/10.1073/pnas.0908686106

Kim D-H, Khatau SB, Feng Y et al (2012) Actin cap associated focal adhesions and their distinct role in cellular mechanosensing. Sci Rep 2:555. https://doi.org/10.1038/srep00555

Kim D-H, Cho S, Wirtz D (2014) Tight coupling between nucleus and cell migration through the perinuclear actin cap. J Cell Sci 127:2528-2541. https://doi.org/10.1242/jcs.144345

Liu P, Zhang YW, Cheng QH, Lu C (2007) Simulations of the spreading of a vesicle on a substrate surface mediated by receptorligand binding. J Mech Phys Solids 55:1166-1181. https://doi. org/10.1016/j.jmps.2006.12.001

Liu X, Liu R, Gu Y, Ding J (2017) Nonmonotonic self-deformation of cell nuclei on topological surfaces with micropillar array. ACS Appl Mater Interfaces 9:18521-18530. https://doi.org/10.1021/ acsami.7b04027

Liu R, Yao X, Liu X, Ding J (2018) Proliferation of cells with severe nuclear deformation on a micropillar array. Langmuir. https://doi. org/10.1021/acs.langmuir.8b03452

Lu H, Koo LY, Wang WM et al (2004) Microfluidic shear devices for quantitative analysis of cell adhesion. Anal Chem 76:5257-5264. https://doi.org/10.1021/ac049837t

Lubarda V (2004) Constitutive theories based on the multiplicative decomposition of deformation gradient: thermoelasticity, elastoplasticity, and biomechanics. Appl Mech Rev 57:95-109

Mammoto T, Ingber DE (2010) Mechanical control of tissue and organ development. Dev Camb Engl 137:1407-1420. https://doi. org/10.1242/dev.024166

Maninova M, Caslavsky J, Vomastek T (2017) The assembly and function of perinuclear actin cap in migrating cells. Protoplasma 254:1207-1218. https://doi.org/10.1007/s00709-017-1077-0

Milan J-L, Lavenus S, Pilet P et al (2013) Computational model combined with in vitro experiments to analyse mechanotransduction during mesenchymal stem cell adhesion. Eur Cell Mater 25:97-113

Mokbel M, Mokbel D, Mietke A et al (2017) Numerical simulation of real-time deformability cytometry to extract cell mechanical properties. ACS Biomater Sci Eng 3:2962-2973. https://doi. org/10.1021/acsbiomaterials.6b00558

Morgan MR, Humphries MJ, Bass MD (2007) Synergistic control of cell adhesion by integrins and syndecans. Nat Rev Mol Cell Biol 8:957-969. https://doi.org/10.1038/nrm2289

Muñoz JJ, Barrett K, Miodownik M (2007) A deformation gradient decomposition method for the analysis of the mechanics of morphogenesis. J Biomech 40:1372-1380. https://doi.org/10.1016/j. jbiomech.2006.05.006

Murtada S-I, Kroon M, Holzapfel GA (2010) A calcium-driven mechanochemical model for prediction of force generation in smooth muscle. Biomech Model Mechanobiol 9:749-762. https ://doi.org/10.1007/s10237-010-0211-0

Nisenholz N, Rajendran K, Dang Q et al (2014) Active mechanics and dynamics of cell spreading on elastic substrates. Soft Matter 10:7234-7246. https://doi.org/10.1039/c4sm00780h

Nobile F, Quarteroni A, Ruiz-Baier R (2012) An active strain electromechanical model for cardiac tissue. Int J Numer Methods Biomed Eng 28:52-71

Nolan DR, Gower AL, Destrade M et al (2014) A robust anisotropic hyperelastic formulation for the modelling of soft tissue. J Mech Behav Biomed Mater 39:48-60. https://doi.org/10.1016/j. jmbbm.2014.06.016
Pan Z, Yan C, Peng R et al (2012) Control of cell nucleus shapes via micropillar patterns. Biomaterials 33:1730-1735. https://doi. org/10.1016/j.biomaterials.2011.11.023

Rodriguez EK, Hoger A, McCulloch AD (1994) Stress-dependent finite growth in soft elastic tissues. J Biomech 27:455-467

Rosenbluth MJ, Lam WA, Fletcher DA (2008) Analyzing cell mechanics in hematologic diseases with microfluidic biophysical flow cytometry. Lab Chip 8:1062-1070. https://doi. org/10.1039/b802931h

Sarvestani AS, Jabbari E (2008) Modeling the kinetics of cell membrane spreading on substrates with ligand density gradient. J Biomech 41:921-925. https://doi.org/10.1016/j.jbiom ech.2007.11.004

Sauer RA (2016) A survey of computational models for adhesion. J Adhes 92:81-120. https://doi.org/10.1080/00218 464.2014.1003210

Schirmer EC, de las Heras JI (eds) (2014) Cancer biology and the nuclear envelope: recent advances may elucidate past paradoxes. Springer, New York

Stålhand J, Klarbring A, Holzapfel GA (2008) Smooth muscle contraction: mechanochemical formulation for homogeneous finite strains. Prog Biophys Mol Biol 96:465-481. https://doi. org/10.1016/j.pbiomolbio.2007.07.025

Storm C, Pastore JJ, MacKintosh FC et al (2005) Nonlinear elasticity in biological gels. Nature 435:191-194. https://doi.org/10.1038/ nature 03521

Swift J, Ivanovska IL, Buxboim A et al (2013) Nuclear lamin-A scales with tissue stiffness and enhances matrix-directed differentiation. Science 341:1240104. https://doi.org/10.1126/ science. 1240104

Tan JL, Tien J, Pirone DM et al (2003) Cells lying on a bed of microneedles: an approach to isolate mechanical force. Proc Natl Acad Sci USA 100:1484-1489. https://doi.org/10.1073/ pnas.0235407100

Versaevel M, Grevesse T, Gabriele S (2012) Spatial coordination between cell and nuclear shape within micropatterned endothelial cells. Nat Commun 3:671. https://doi.org/10.1038/ncomms1668

Wang H, Biao Y, Chunlai Y, Wen L (2017) Simulation of AFM indentation of soft biomaterials with hyperelasticity. In: 2017 IEEE 12th international conference on nano/micro engineered and molecular systems (NEMS), pp 550-553

Wolf K, Te Lindert M, Krause M et al (2013) Physical limits of cell migration: control by ECM space and nuclear deformation and tuning by proteolysis and traction force. J Cell Biol 201:10691084. https://doi.org/10.1083/jcb.201210152

Yeoh OH (1993) Some forms of the strain energy function for rubber. Rubber Chem Technol 66:754-771. https://doi. org/10.5254/1.3538343

Zeng X, Li S (2011a) Modelling and simulation of substrate elasticity sensing in stem cells. Comput Methods Biomech Biomed Eng 14:447-458. https://doi.org/10.1080/10255842.2011.557371

Zeng X, Li S (2011b) Multiscale modeling and simulation of soft adhesion and contact of stem cells. J Mech Behav Biomed Mater 4:180-189. https://doi.org/10.1016/j.jmbbm.2010.06.002

Zeng X, Li S (2012) A three dimensional soft matter cell model for mechanotransduction. Soft Matter 8:5765-5776. https://doi. org/10.1039/c2sm07138j 